\title{
Unexpected requirement for a binding partner of the syntaxin family in phagocytosis by murine testicular Sertoli cells
}

\author{
Y-s Dong ${ }^{1,2,6}$, W-g Hou ${ }^{3,6}$, Y Lił ${ }^{4,6}$, D-b Liu ${ }^{4}$, G-z Hao ${ }^{1}$, H-f Zhang ${ }^{1}$, J-c Li ${ }^{1}$, J Zhao ${ }^{2}$, S Zhang ${ }^{5}$, G-b Liang ${ }^{\star, 1}$ and W Li,2
}

Testicular phagocytosis by Sertoli cells (SCs) plays an essential role in the efficient clearance of apoptotic spermatogenic cells under both physiological and pathological conditions. However, the molecular mechanism underlying this unique process is poorly understood. Herein, we report for the first time that $\alpha$-taxilin protein (TXLNA), a binding partner of the syntaxin family that functions as a central player in the intracellular vesicle traffic, was dominantly expressed in SCs. Induction of apoptosis in murine meiotic spermatocytes and haploid spermatids by busulfan treatment stimulated a significant increase of TXLNA in SCs at day (d) 14 and d 24 after busulfan treatment, respectively. Consistently, TXLNA expression was steadily upregulated when SCs were co-cultured with apoptotic germ cells (GCs). Moreover, using siRNA treatment, we found that ablation of endogenous TXLNA significantly impaired the phagocytotic capacity of SCs and thereby resulted in defective spermiogenesis and reduced fertility during the late recovery after testicular heat stress. Mechanistically, upregulation of TXLNA expression by apoptotic GCs was associated with the stabilization of ATP-binding cassette transporter 1 (ABCA1), a transporter-mediated lipid efflux from SCs and influencing male fertility. TXLNA acted as an upstream suppressor of ABCA1 ubiquitination and thus promoted ABCA1 stability and accumulation following GC apoptosis. We further provide in vitro evidence that epidermal growth factor receptor (EGFR)mediated phosphorylation regulated ABCA1 ubiquitination and was enhanced by TXLNA deficiency during testicular phagocytosis. Taken together, the TXLNA/ABCA1 cascade may serve as an important feedback mechanism to modulate the magnitude of subsequent phagocytotic process of SCs in response to testicular injury.

Cell Death and Differentiation (2016) 23, 787-800; doi:10.1038/cdd.2015.139; published online 23 October 2015

During mammalian spermatogenesis, more than $75 \%$ of developing spermatogenic cells undergo apoptosis before maturation. ${ }^{1}$ Moreover, under certain pathological conditions, apoptosis is very likely to occur in specific germ cells (GCs). ${ }^{2}$ De facto the quantity of GCs is tightly regulated to match the supportive capacity of Sertoli cells (SCs). Thus, the tight control of ratio of GCs to SCs via apoptosis is required for spermatogenesis. Although the occurrence of apoptosis at various stages of spermatogenesis is frequently observed, few apoptotic GCs are histochemically detectable in normal adult testis. This is most probably due to the rapid elimination by phagocytosis. ${ }^{3}$ This phagocytic action is necessary for maintaining testicular homeostasis under both physiological and pathological conditions. ${ }^{4}$ Although the investigation of these phenomena has recently become more intensive, most mechanisms still remain obscure.

The taxilin family, composed of at least three isoforms including $\alpha-, \beta$ - and $\gamma$-taxilin, is a binding partner of the syntaxin family, which functions as a central player in intracellular vesicle traffic. Many researchers have shown that $a$-taxilin protein (TXLNA) is overexpressed in various tumor cells and its expression is correlated with metastatic potential. ${ }^{5}$ Besides its malignancy-promoting effects, growing evidence strongly suggests that peripheral actions of TXLNA are likely to take place. In this sense, the involvement of TXLNA in cell proliferation of murine gastrointestinal tract has been reported recently. ${ }^{5}$ TXLNA is ubiquitously expressed. ${ }^{6}$ However, the physiological relevance of TXLNA signaling in such peripheral systems remains largely unknown.

ATP-binding cassette transporter 1 (ABCA1), a regulator of choline-phospholipid and cholesterol efflux to high-density lipoprotein (HDL), plays an essential role in hepatic metabolism. Studies suggest that vesicular transport is associated with $A B C A 1$ function. ${ }^{7} A B C A 1$ interacts with syntaxin 13 and flotillin-1, and this interaction enhanced phagocytosis in Tangier cells. ${ }^{8}$ In testis, ABCA1 is predominantly expressed in SCs. Loss of ABCA1 is associated with impaired male

\footnotetext{
${ }^{1}$ Department of Neurosurgery, General Hospital of Shenyang Military Area Command, Shenyang 110016, China; ${ }^{2}$ Department of Histology and Embryology, Fourth Military Medical University, Xi'an 710032, China; ${ }^{3}$ Department of Anesthesiology, Xijing Hospital, Fourth Military Medical University, Xi'an 710032 , China; ${ }^{4}$ Department of Air Logistics, 463rd Hospital of PLA, Shenyang 110042, China and ${ }^{5}$ Department of Gynecology and Obstetrics, Reproductive Medicine Center, Tangdu Hospital, Fourth Military Medical University, X'an 710038, China

${ }^{*}$ Corresponding author: W Li, Department of Histology and Embryology, Fourth Military Medical University, No. 169 Changle West Road, Xi'an 710032, China. Tel: +86 29 84774511; E-mail: liweipepeyato@ 163.com

or G-b Liang, Department of Neurosurgery, General Hospital of Shenyang Military Area Command, No. 83 Wenhua Road, Shenhe District, Shenyang 110016, China. Tel: +86 24 28897431; E-mail: liangguobiaosz@163.com

${ }^{6}$ These authors contributed equally to this work.

Abbreviations: GCs, germ cells; SCs, Sertoli cells; TXLNA, $\alpha$-taxilin protein; ABCA1, ATP-binding cassette transporter 1; HDL, high-density lipoprotein; CK18, intermediate filament protein cytokeratin 18; HS, heat stress; EGFR, epidermal growth factor receptor; Cbl, casitas B-lineage lymphoma

Received 11.3.15; revised 14.9.15; accepted 25.9.15; Edited by M Piacentini; published online 23.10.15
} 
fertility due to the disruption of lipid efflux from SCs. ${ }^{9}$ These data are indicative of a unique role of ABCA1 in SCs.

Phagocytotic action requires a lot of intracellular trafficking events. ${ }^{10}$ The identification of TXLNA as an integral part of intracellular vesicle traffic complexes prompted us to evaluate whether this signal is functionally expressed in testis. A systematic study comprising multiple analyses was next designed to elucidate the potential role of this syntaxin partner in SC phagocytosis. Furthermore, since TXLNA and ABCA1 are both strongly associated with syntaxin function, we evaluated the potential functional link between TXLNA and ABCA1.

\section{Results}

Distinctive expression of TXLNA in mouse SCs. Immunoblotting analysis of protein lysates prepared from 3T3 cells, revealed a single band with the predicted size of $\sim 70 \mathrm{kDa}$ in

a

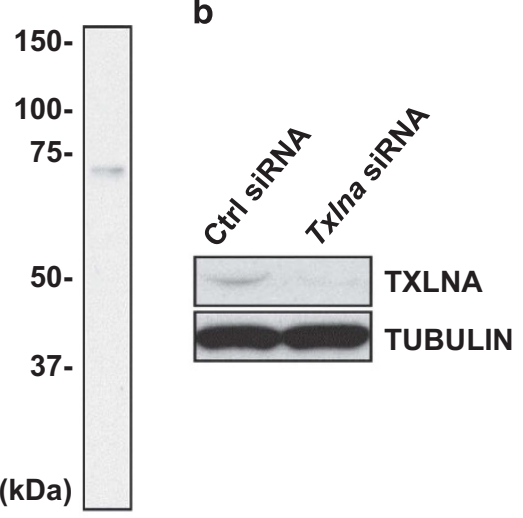

the whole blot (Figure 1a). Targeted knockdown of TxIna in 3T3 cells by siRNA led to decreased expression of TXLNA (Figures $1 \mathrm{~b}$ and $\mathrm{c}$ ), confirming the antibody specificity. Immunohistochemistry evidenced the predominant presence of the TXLNA signal in the SCs (black arrows in Figure 1d). In another experimental setting, TXLNA was exclusively expressed in primary SCs. In contrast, no signals were detected in GCs, TM3 Leydig cell line, TM4 SC line or caudal sperms (Figure 1e). The intermediate filament protein cytokeratin 18 (CK18), a marker of immature SCs, decreased markedly from peripubertal postnatal day (d) $23 .{ }^{11}$ Concomitantly, TXLNA expression was initiated from postnatal d 23 onwards (Figure 1f), exhibiting a precisely controlled appearance of TXLNA in functionally mature SCs.

Tight regulation of TXLNA expression by proper GC associations. To elucidate the effect of GCs on the TXLNA

C

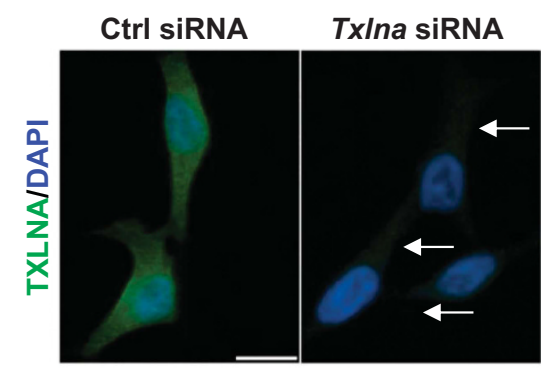

d

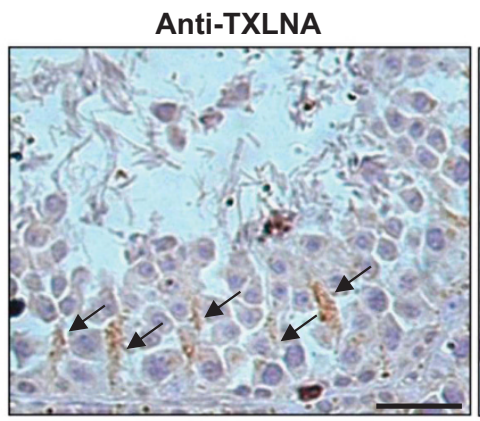

e

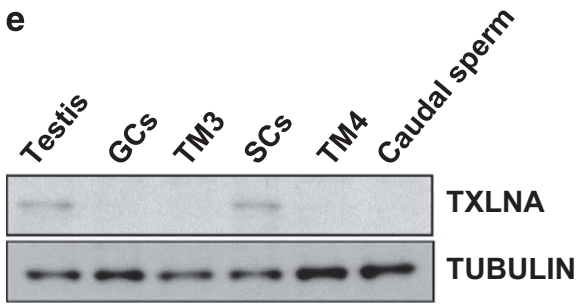

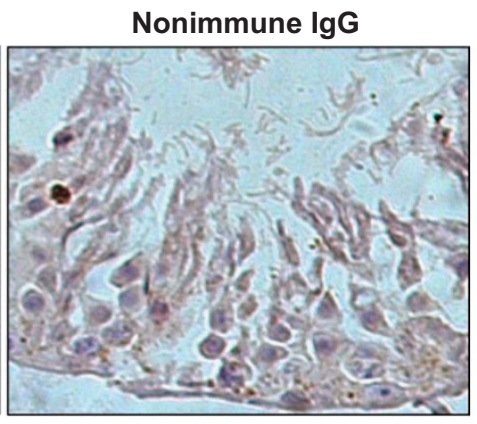

f

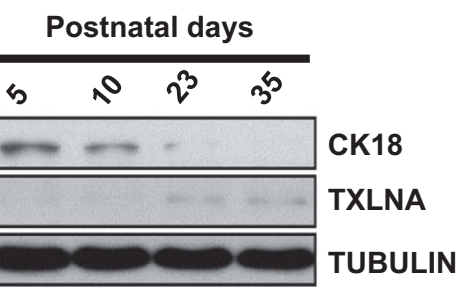

Figure 1 TXLNA is predominantly expressed in functionally mature Sertoli cells (SCs). (a) Immunoblotting analysis demonstrated a single band of TXLNA protein in the testicular lysates, which was absent when samples were incubated with preabsorbed primary antibody or without primary antibody. (b) The efficiency of the targeted knockdown of TxIna in 3 T3 cells was confirmed by western blotting at the translational level. Tubulin served as a loading control. (c) The efficiency of the targeted knockdown of Tx/na in 3T3 cells was also confirmed by immunofluorescence staining. Arrows indicate positive signals of TXLNA protein. Scale bar, $10 \mu \mathrm{m}$. (d) Immunohistochemical analysis in murine testes revealed a distinct cytoplasm localization of TXLNA in SCs (arrows). Replacement of the primary antibody with nonimmune lgG abolished the immunostaining, confirming the specificity of the assay. Scale bar, $25 \mu \mathrm{m}$. (e) Expression profile of TXLNA was evaluated in different spermatogenic cell lines and in mouse testis using western blotting. Tubulin served as a loading control. (f) Immunoblotting analysis of TXLNA and CK18 protein in mouse developing postnatal testis. Tubulin served as a loading control 
expression, we treated mice with busulfan. In line with the previous report, ${ }^{12}$ most tubules were devoid of GCs by posttreatment d 30 (Figure 2a). GC depletion occurred mainly through the induction of apoptosis (Figure 2b), which appeared from post-treatment $d 7$ and reached the maximum level at $14 \mathrm{~d}$ (Figure 2c). To identify at which stage the differentiation of GCs was blocked, we performed qRT-PCR analyses using specific primers for mouse Sohlh2 (differentiating spermatogonia), for mouse Cana1 (late pachytene spermatocytes) and for mouse Dbil5 (round/ elongating/elongated spermatid), respectively. ${ }^{13}$ The significant decrease in different markers was observed at distinct time points: d 7 for Sohlh2, d 14 for Cana1 and d 24 for Dbil5 (Figure 2d), indicative of a gradually developed cytotoxic effect on specific GCs. Interestingly, TXLNA expression was significantly augmented when apoptosis in pachytene a

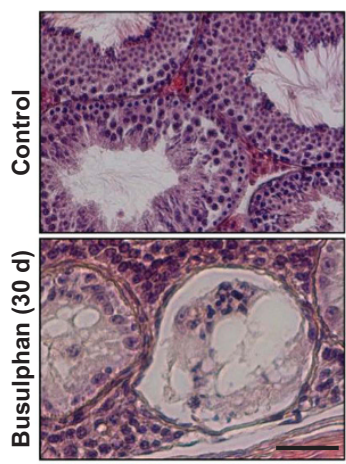

C

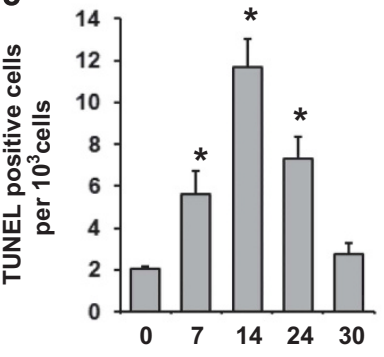

Days after busulphan treatment

Days after

busulphan treatment

$\begin{array}{lllll}0 & 7 & 14 & 24 & 30\end{array}$

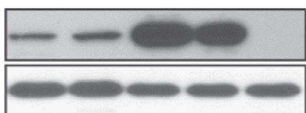

TXLNA

TUBULIN b

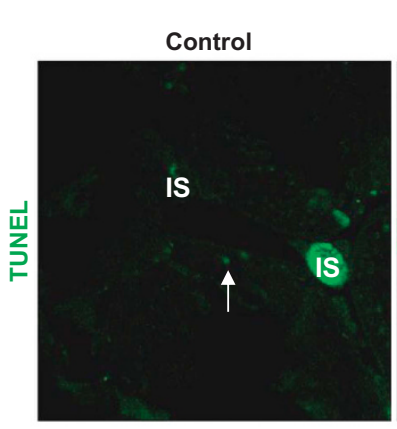

d

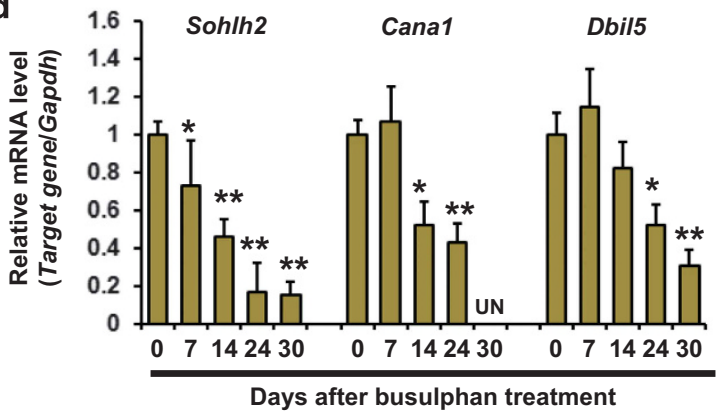

9 Time after GCs addition

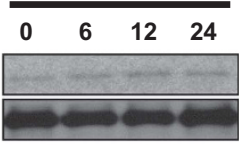

Time after apoptotic GCs addition

$\begin{array}{llll}0 & 6 & 12 & 24\end{array}$

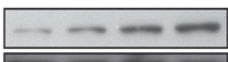

f

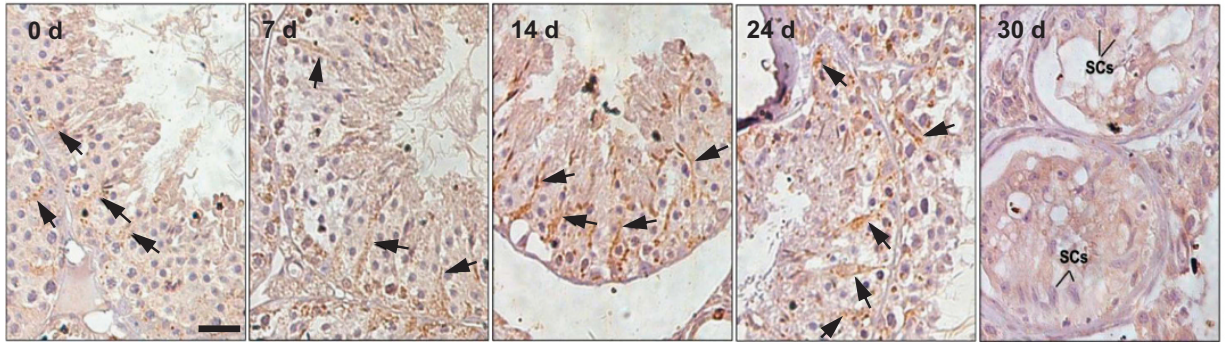

Figure 2 Presence of TXLNA in SCs is required for proper contact between SCs and adjacent germ cells (GCs). (a) Tissue sections show morphology in control testes and busulfan-treated testes $30 \mathrm{~d}$ after treatment. At this time point, seminiferous tubules were largely devoid of GCs. Scale bar, $25 \mu \mathrm{m}$. (b) TUNEL staining of testicular sections was carried out at $14 \mathrm{~d}$ after busulfan treatment. Nuclear green signal indicates apoptotic cells (white arrows). IS, testicular interstitium. Scale bar, $25 \mu \mathrm{m}$. (c) Quantification of TUNELpositive cells. Results are expressed as mean \pm S.E.M.; $n=3$ independent experiments $\left({ }^{*} P<0.05\right.$, when compared to the value at $0 \mathrm{~d}$, Student's $t$-test). (d) The deleterious effects of busulfan treatment on the spermatogenic differentiation at different time points was evaluated by qRT-PCR analyses using specific primers for mouse Soh/h2 (differentiating spermatogonia), for mouse Ccna1 (pachytene spermatocytes) and for mouse Dbil5 (haploid spermatids), respectively. Gapdh served as an internal control. Results presented as mean \pm S.E.M. of three independent experiments. $\left({ }^{*} P<0.05\right.$ or ${ }^{* *} P<0.01$, when compared to the value at $0 \mathrm{~d}$, Student's $t$-test). (e) Effect of busulfan treatment on testicular TXLNA expression was monitored using immunoblotting analyses. Tubulin served as a loading control. (f) Localization of testicular TXLNA protein at different time points after busulfan treatment was evaluated using immunohistochemistry. Scale bar, $25 \mu \mathrm{m}$. (g) Western blotting analysis of TXLNA protein in cultured SCs at different time points after incubation with freshly isolated GCs or with apoptotic GCs. Tubulin was used as a loading control 
spermatocytes and haploid spermatids began to occur at $d$ 14 and 24, respectively. In contrast, TXLNA expression was totally abolished when most tubules contained only SCs by $\mathrm{d}$ 30 (Figure 2e). Consistently, the TXLNA-positive staining in the SCs, located in peritubular regions characterized by dendritic processes extending toward the tubular center, was enhanced at post-treatment $\mathrm{d} 14$ and 24, when compared to that at other time points (black arrows in Figure 2f). Efficient phagocytic clearance of apoptotic GCs by adjacent SCs is crucial for functional mature spermatogenesis. ${ }^{14}$ We incubated primary cultured SCs with freshly isolated GCs or apoptotic GCs. Subsequent immunoblotting analyses only revealed a time-dependent increase in the TXLNA expression in the SCs co-cultured with apoptotic GCs (Figure 2g). These data collectively confirmed the potential involvement of TXLNA in testicular phagocytosis.

Requirement for TXLNA in apoptotic cell clearance. To test whether TXLNA directly participates in SC phagocytosis, we knocked down the expression of endogenous TXLNA in adult testis by using a specific siRNA. TxIna siRNA and Ctrl siRNA were daily administrated by intraperitoneal (i.p.) injection during $10 \mathrm{~d}$ (Figure 3a), according to a previously validated protocol. ${ }^{15}$ TxIna depletion was confirmed by qRT-PCR (Figure 3b), western blotting (Figure 3c) and immunohistochemistry (Figure $3 d$ ). An $\sim 40 \%$ decrease of TxIna/TXLNA was detected at the end of $25 \mathrm{~d}$ after siRNA treatment. To study the effects of TXLNA ablation on testicular phagocytic activity, we treated mice with a single, mild, transient scrotal heat stress (HS). ${ }^{16}$ At post-HS $24 \mathrm{~h}$ or $14 \mathrm{~d}$, testes were harvested and subjected to apoptotic analyses. These two time points were chosen because HS-induced apoptosis increases to the maximum level at about $24 \mathrm{~h}$, and then disappears by $14 \mathrm{~d}{ }^{17}$ Histological examinations revealed a significant increase in the apoptotic GCs at post-treatment $24 \mathrm{~h}$ (black arrows in Supplementary Figure 1). In contrast, multinucleated giant cells (black arrowheads in Supplementary Figure 1) and vacuolar spaces ('V' in Supplementary Figure 1), instead of apoptotic GCs, were frequently observed at post-treatment $14 \mathrm{~d}$. Although most of the GCs die by apoptosis in response to $\mathrm{HS},{ }^{18}$ very low apoptotic wave was seen in the testes treated with Ctrl SiRNA at $14 \mathrm{~d}$. In our study, the testes treated with TxIna siRNA exhibited a significantly higher level of apoptosis at both post-treatment $24 \mathrm{~h}$ and $14 \mathrm{~d}$ (Figures $3 e$ and f). Most of the apoptotic GCs were identified as primary spermatocytes because TUNEL signals were perfectly overlapped with cyclin A1 staining (Figure $3 g$ ). Because SCs show strong phagocytic activities toward apoptotic GCs and residual bodies (RBs), ${ }^{14}$ we next determined the requirement of TXLNA for SC phagocytosis at the in vitro level. We knocked down the expression of endogenous TXLNA using siRNA (Figure 3h). We then incubated these SCs with biotin-labeled RBs. Interestingly, the 6-h incubation of RBs elicited a gradual and steady increase in the binding and phagocytic activities in the Ctrl siRNA-treated SCs, but not in the TxIna siRNA-treated SCs (Figures $3 i$ and j). Thus, TXLNA deficiency significantly impaired the ability of SCs to bind and engulf apoptotic GCs.

\section{Lack of TXLNA in SCs causes defective development} during recovery from $\mathrm{HS}$. We carried out the mating experiments at the end of $35 \mathrm{~d}$ (one spermatogenic cycle, short-term effect) or at the end of $70 \mathrm{~d}$ (two spermatogenic cycles, long-term effect) ${ }^{19}$ after HS (Figure 4a). The fertility potential was both substantially impaired in Ctrl siRNA or TxIna siRNA-treated mice $35 \mathrm{~d}$ after HS. However, the impregnation rate of TxIna siRNA-treated mice remained significantly reduced even after long-term recovery. Asthenozoospermia, not oligozoospermia, appeared to account for this fertility impairment (Figure 4b). In addition, at $70 \mathrm{~d}$ after HS, sperm from TxIna siRNA-treated mice was morphologically highly abnormal, with head and tail abnormalities in $40 \pm 11 \%$ and $13 \pm 5 \%$ of sperm, respectively, whereas head or tail defects were found in only $21 \pm 6 \%$ of sperm from Ctrl siRNA-treated mice (Figure 4c). Defects in sperm heads included amorphous forms, head loss and lack of the usual hook (Figure 4d; b', $c^{\prime}$ and $d^{\prime}$ ). Tail defects manifested with folded sperm or as bundled tails (Figure $4 d ; d^{\prime}, e^{\prime}$ and $f^{\prime}$ ). These data suggest that TXLNA deficiency in SCs may impede testicular restoration from HS, thereby causing astheno-teratozoospermia. We then assessed body weights, fasting plasma levels of serum cholesterol (total cholesterol), triglycerides and glucose and serum levels of sex hormones at fed state. None of these metabolic/hormonal parameters differed significantly between two experimental groups (Supplementary Figure 2), further excluding the toxicity of the systemic administration of siRNA.

Inhibition of TXLNA promotes ubiquitination of ABCA1 during phagocytosis by SCs. Phagocytosis of apoptotic spermatogenic cells results in the formation of lipids, which

Figure 3 Requirement of TXLNA for testicular phagocytosis. (a) Schematic representation of the experimental procedures used in the in vivo study. In vivo siRNA for ablation of endogenous TxIna in testis was carried out as described in Materials and Methods. Animals were injected i.p. daily for $10 \mathrm{~d}$ with $100 \mu$ l of solution of siRNA in isotonic saline solution ( $3 \mu \mathrm{g}$ per mouse), followed by testicular heat treatment. At $24 \mathrm{~h}$ or $14 \mathrm{~d}$ after heat exposure, mice were killed and testicular samples were subjected to different experimental assays. Effects of endogenous TxIna knockdown in testis by in vivo siRNA treatment were confirmed by qRT-PCR at transcriptional level (b) and by western blotting at translational level (c); Gapdh and tubulin were served as internal controls. Data are presented as mean \pm S.E.M. of $\geq 3$ independent determinations. ${ }^{*} P<0.05$. (d) Localization of testicular TXLNA protein at different time points after heat stress was evaluated using immunohistochemistry. Positive signals were denoted using black arrows. Scale bar, $25 \mu \mathrm{m}$. (e) TUNEL staining of testicular sections at different time points after heat stress. (f) Quantification of TUNEL-positive cells. ${ }^{*} P<0.05$ or ${ }^{* *} P<0.01$ when compared to the value of sham control. (g) Combined TUNEL (green, arrowheads) and double immunofluorescence labeling suggests apoptotic GCs at the end of $24 \mathrm{~h}$ after heat treatment were pachytene spermatocytes as indicated by the overlapping staining of cyclin A1 signal (red, arrows). Scale bar, $20 \mu \mathrm{m}$. (h) Effect of endogenous Tx/na knockdown in cultured SCs by in vitro siRNA treatment were confirmed using western blotting. (i) Representative pictures of residual bodies (RBs) binding and phagocytized by Ctrl siRNA or Tx/na siRNAtreated SCs $4 \mathrm{~h}$ after addition of RBs. Arrowheads denote the ingested RBs, whereas empty arrowheads denote the plasma membrane-bound RBs. Scale bar, $10 \mu \mathrm{m}$. (j) Kinetics of RBs binding and phagocytosis by SCs (the binding and phagocytosis index) were calculated as the ratio of positive green signals/nuclei number in each well. Values represent the mean \pm S.E.M. of three independent experiments $\left({ }^{*} P<0.05\right.$ or ${ }^{\star *} P<0.01$, when compared to the value at $2 \mathrm{~h}$ ) 
a

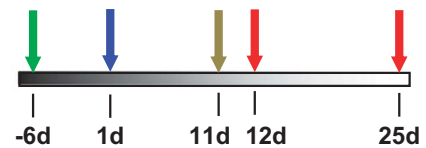

I - - - - $-\overline{-}-\overline{-}-\overline{-}-1$

$I \leftarrow$ Daily injection for 10 days

I $(3 \mu \mathrm{g} /$ mouse, $n=5)$

I $\leftarrow$ Heat stress (HS)

I $\leftarrow$ Termination of treatment I

- - - - - - - - -

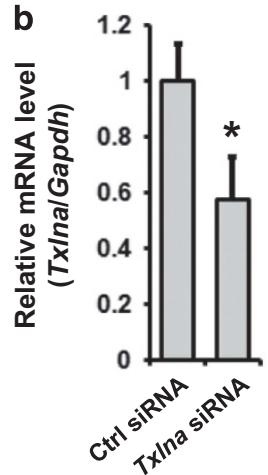

C

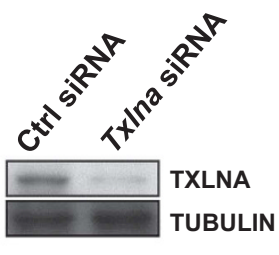

TUBULIN d

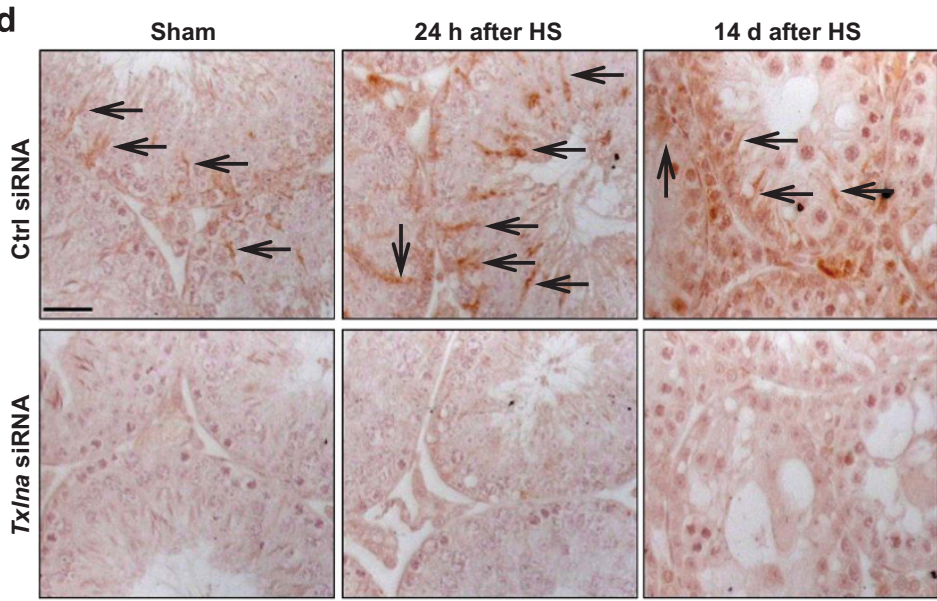

e

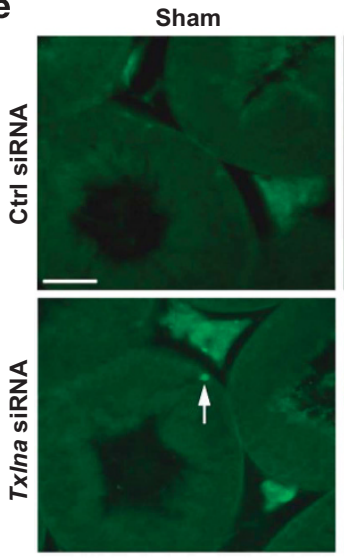

$24 \mathrm{~h}$ after HS
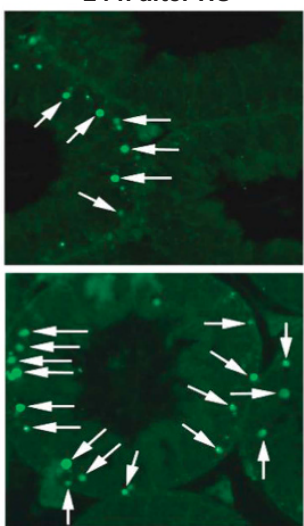

$14 \mathrm{~d}$ after HS
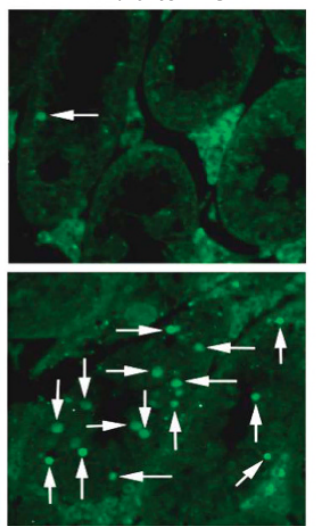

g

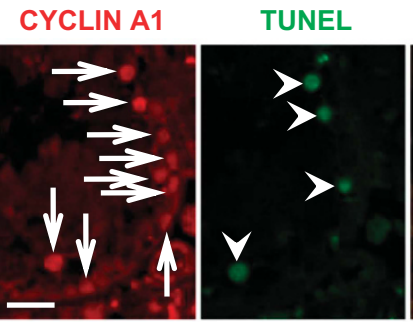

Merge

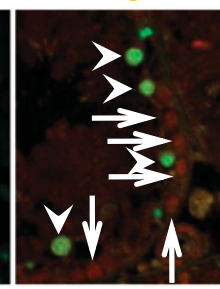

h
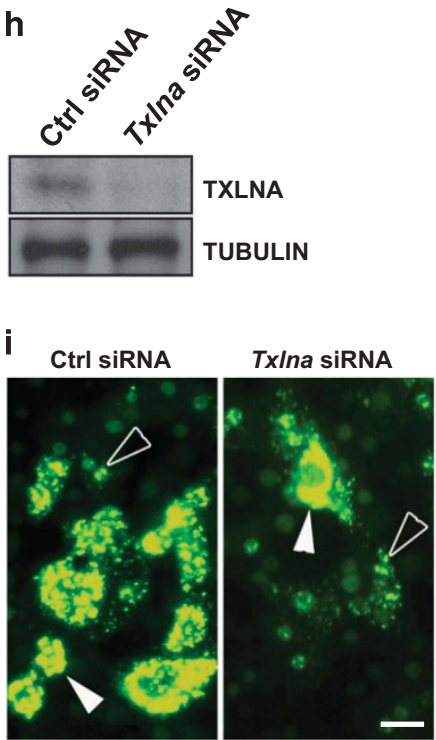

j

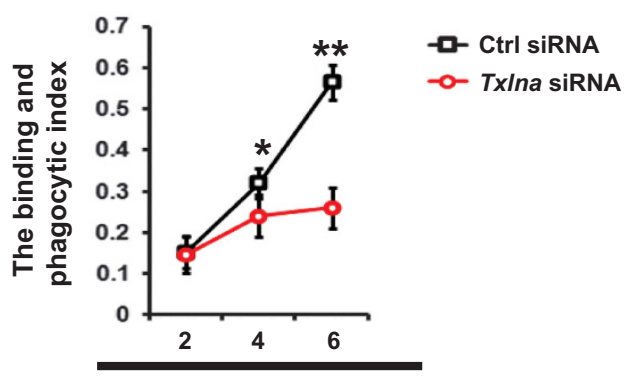

Time after GCs addition (h) 
a

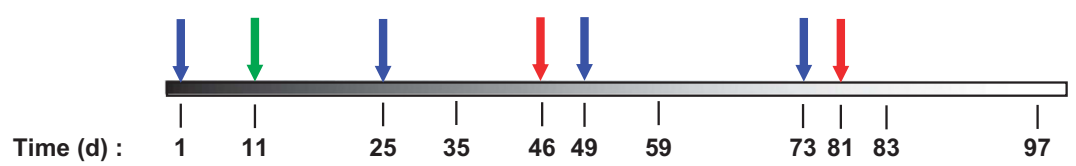

Time (d) :

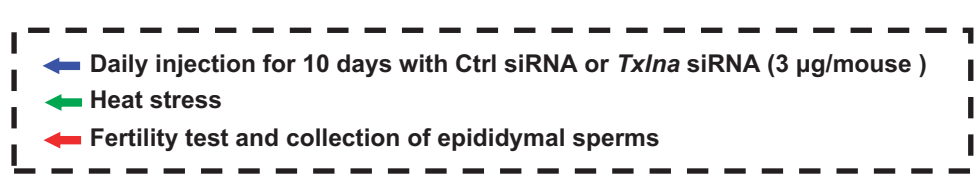

b

\begin{tabular}{|c|c|c|c|c|c|c|}
\hline \multirow{2}{*}{\multicolumn{2}{|c|}{ Experimental groups }} & \multicolumn{3}{|c|}{ Reproductive capacity } & \multicolumn{2}{|c|}{$\begin{array}{c}\text { Characteristics of epididymal } \\
\text { sperms }\end{array}$} \\
\hline & & $\begin{array}{l}\text { Pregnancies/ } \\
\text { females mated }\end{array}$ & Litter size & $\begin{array}{l}\text { Number } \\
\text { of males } \\
\text { mated }\end{array}$ & $\begin{array}{c}\text { Number of } \\
\text { sperm } \\
\left(10^{6} / \text { epididymis }\right)\end{array}$ & $\begin{array}{l}\text { Progressive } \\
\text { motility (\%) }\end{array}$ \\
\hline & Control & $36 / 42(85.7 \%)$ & $7.88 \pm 1.25^{a}$ & 8 & $30.49 \pm 1.47^{a}$ & $34.32 \pm 2.27^{a}$ \\
\hline \multirow{2}{*}{$\begin{array}{l}35 \mathrm{~d} \\
\text { after } \\
\text { heat } \\
\text { stress }\end{array}$} & $\begin{array}{l}\text { Ctrl siRNA } \\
+ \text { heat stress }\end{array}$ & $13 / 56(23.2 \%)$ & $3.80 \pm 1.32^{b}$ & 10 & $11.76 \pm 2.04^{b}$ & $15.17 \pm 7.94^{b}$ \\
\hline & $\begin{array}{l}\text { TxIna siRNA } \\
\text { + heat stress }\end{array}$ & $11 / 52(21.2 \%)$ & $4.00 \pm 2.05^{b}$ & 10 & $12.14 \pm 1.95^{b}$ & $17.97 \pm 7.20^{b}$ \\
\hline \multirow{2}{*}{$\begin{array}{l}70 \mathrm{~d} \\
\text { after } \\
\text { heat } \\
\text { stress }\end{array}$} & $\begin{array}{l}\text { Ctrl siRNA } \\
+ \text { heat stress }\end{array}$ & $35 / 54(64.8 \%)$ & $6.90 \pm 1.19^{a}$ & 10 & $23.18 \pm 3.58^{b}$ & $32.64 \pm 3.27^{a}$ \\
\hline & $\begin{array}{l}\text { TxIna siRNA } \\
+ \text { heat stress }\end{array}$ & $17 / 54(31.5 \%)$ & $4.80 \pm 1.87^{b, c}$ & 10 & $22.54 \pm 3.23^{b}$ & $21.81 \pm 3.29^{b, c}$ \\
\hline
\end{tabular}

${ }^{b,} P<0.01$ when compared to control; ${ }^{c,} P<0.01$ when compared to Ctrl siRNA at the same time point

C
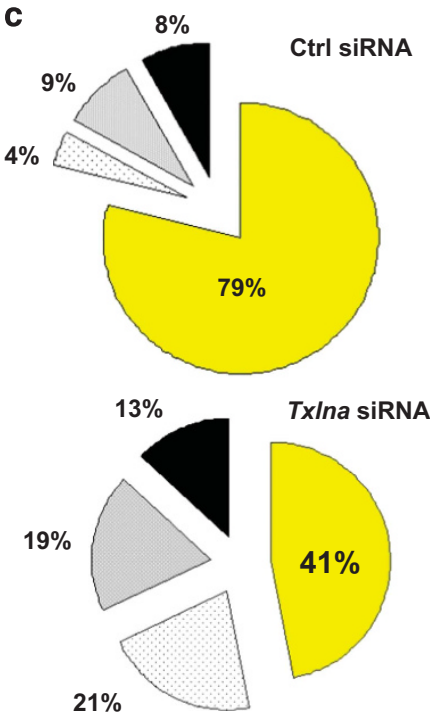

d

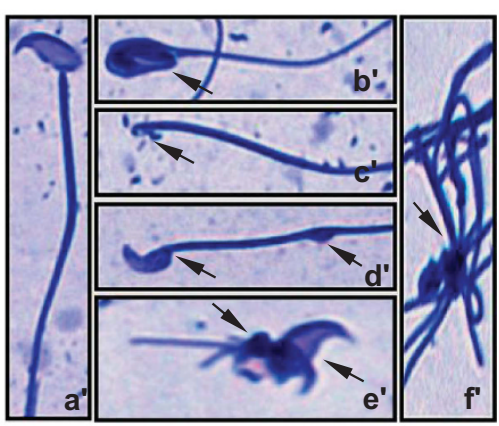

Normal shape (falciform)

Headless

Irregularly shaped head

Partly coiled intracellularly

Figure 4 Consequences of in vivo knockdown of TxIna in mouse testicular recovery after heat stress. (a) Schematic representation of the experimental procedure used in the in vivo study. In vivo siRNA for ablation of endogenous TxIna in testis was carried out as described above, followed by a 14-d break. Mice received four cycles of in vivo siRNA treatment. At 35 or $70 \mathrm{~d}$ after heat treatment, mice were killed. Fertility test and assessment of epididymal sperms were carried out as described in Materials and Methods (b). (c) Pie charts showing multiple sperm types and shapes in Ctrl siRNA or TxIna siRNA-treated mice $70 \mathrm{~d}$ after heat treatment. Two hundred sperm cells were analyzed for each genotype. (d) Representative examples of abnormal morphology of sperm from TxIna siRNA-treated mice at $70 \mathrm{~d}$ after heat stress. $\mathrm{a}^{\prime}$, normal sperm; $b^{\prime}$, amorphous forms of head; $c^{\prime}$, head loss; $d^{\prime}$, lack of the usual hook; $e^{\prime}$, folded tail; $f^{\prime}$, bundled tails. Arrows indicate morphological abnormalities 
are further metabolized to produce ATP in SCs. ${ }^{4}$ Deregulated metabolism of the lipid droplets is the hallmark of disrupted SC function. ${ }^{20}$ At $35 \mathrm{~d}$ after HS, the number of lipid droplets in SCs increased significantly in TxIna siRNA-treated males, whereas lipid droplets were scarcely found inside the seminiferous tubules from sham controls or Ctrl siRNAtreated mice. Interestingly, the increase of lipid droplets appeared to be reversely correlated to the ABCA1 expression in SCs during recovery (Figure 5a). Because ABCA1 plays an important role in lipid transport in SCs and influences male fertility, ${ }^{9}$ we asked whether the above-mentioned phenotype was caused by the deregulation of ABCA1 expression. Six-hour incubation of SCs with apoptotic GCs significantly stimulated ABCA1 expression at both transcriptional and translational level (Figures $5 b$ and $c$ ). Unexpectedly, the upregulation of $A B C A 1$ expression by apoptotic GCs required the endogenous TXLNA in SCs (Figure 5d). ABCA1 degradation is mediated through ubiquitination, ${ }^{21}$ which was evidenced in our study that 6-h incubation with apoptotic GCs substantially abolished ABCA1 ubiquitination in SCs (Figure 5e). However, in TXLNA-deficient SCs (Figure 5f), ABCA1 ubiquitination was constantly observed regardless of the presence of apoptotic GCs (Figure $5 \mathrm{~g}$ ). We next investigated the effect of ablation of endogenous Abca1 on $\mathrm{SC}$ phagocytosis. Immunoblotting analysis demonstrated that si-2 was more effective in suppressing the expression of ABCA1 (Figure 5h), and it was therefore selected for further studies. Interestingly, selective knockdown of Abca1 in SCs impaired the binding and phagocytic activity at the end of $6 \mathrm{~h}$ after RB incubation (Figure 5i). Treatment with T0901317 selectively increases $A B C A 1$ expression. ${ }^{22}$ We therefore used T0901317 to rescue ABCA1 level in TXLNA-deficient SCs (Figure 5j). TO901317 treatment of TXLNA (-/-) SCs to normalize ABCA1 expression substantially restored the binding and phagocytic activity at the end of $6 \mathrm{~h}$ after RB incubation (Figure 5k). Thus, it is very likely that the instability of $A B C A 1$ due to excessive ubiquitinated degradation may be terminally responsible for the dyszoospermia caused by TXLNA deficiency in SCs.

Epidermal growth factor receptor (EGFR)-mediated phosphorylation regulates ABCA1 ubiquitination and is enhanced by TXLNA deficiency. Recent advances have shown that EGFR signaling plays a pivotal role during autophagy. ${ }^{23}$ Although autophagy and phagocytosis are activated by different mechanisms, their final steps converge on similar pathways that are regulated by shared molecules. ${ }^{24}$ In this context, we wonder whether EGFR is involved in the regulation of ABCA1 stability by TXLNA. We measured EGFR phosphorylation status during SC phagocytosis. Incubation of primary SCs with apoptotic GCs for 45 min resulted in marked phosphorylation of multiple sites in EGFR. TxIna ablation further stimulated the phosphorylation of Thr-845 and Ser1046/1047 (Figure 6a), indicating that these two sites may be the candidate sites for TXLNAmediated regulation of EGFR phosphorylation. We then examined the colocalization of EGFR and ABCA1 in primary cultured SCs upon GC incubation. In the absence of GC stimulation, almost all EGFR localized to the cell surface and cytoplasm, and did not colocalize with ABCA1. In contrast, after GC stimulation, EGFR was observed in punctate intracellular vesicles and colocalized with ABCA1 (Figure 6b). We next examined the direct association between activated EGFR and ABCA1 during testicular phagocytosis. Incubation of primary SCs with apoptotic GCs for $6 \mathrm{~h}$ induced EGFR phosphorylation and thereafter enhanced the interaction between EGFR and ABCA1. These stimulatory effects were augmented in TXLNA-deficient SCs. Interestingly, enhancement of EGFR phosphorylation/EGFR$A B C A 1$ interaction could result in a dramatic decrease of endogenous $A B C A 1$. In contrast, treatment with EGFR selective inhibitor PD168393 blocked EGFR activity, abolished the EGFR-ABCA1 interaction and thereby partially reversed $A B C A 1$ reduction (Figure $6 \mathrm{c}$ ). These data suggest that the interaction of active EGFR and ABCA1 may be responsible for the ABCA1 instability in TXLNA-deficient SCs during phagocytosis. To further evaluate whether liganddependent and -independent activation of EGFR results in the formation of an EGFR-ABCA1 complex, we used HeLa cells that express low levels of endogenous EGFR and were negative for ABCA1 expression. ${ }^{25,26}$ HeLa cells were transfected either with WT EGFR, which requires EGF stimulation for EGFR phosphorylation and activation, or with constitutively active mutants of EGFR ( $\triangle 790 \mathrm{M}$; Supplementary Figure 3 ). WT EGFR coimmunoprecipitated with overexpressed $A B C A 1$ only when activated by EGF stimulation, whereas the constitutively active mutant EGFR coimmunoprecipitated with $\mathrm{ABCA} 1$ in the absence of EGF stimulation. As expected, supplement with PD168393 blocked EGFR phosphorylation and abolished the EGFRABCA1 interaction (Figure 6d). Thus, both ligand-dependent stimulation of WT EGFR and activating mutations in EGFR could promote the formation of an EGFR-ABCA1 complex. Subsequent efforts were focused on whether EGFR increased phosphorylation of serine, threonine or tyrosine residues in ABCA1 using phosphoamino acid-specific antibodies, because these sites have been shown to target signaling pathways that may alter ABCA1 stability or activity. ${ }^{27-29}$ Immunoblots of immunoprecipitated ABCA1 showed that GC incubation increased phosphorylation of serine but not threonine or tyrosine (Figure 6e). Because Ser2054 alone has been shown to be crucial for regulation of ABCA1 transporter activity, ${ }^{29}$ we then focused on this site and monitored its phosphorylation status using the specific antibody. In HeLa cells, WT EGFR coimmunoprecipitated with overexpressed $A B C A 1$ and phosphorylated $\mathrm{ABCA} 1^{\text {Ser2054 }}$ only when activated by EGF stimulation. In contrast, the constitutively active EGFR mutant coimmunoprecipitated with $A B C A 1$ in the absence of EGF stimulation and resulted in a more phosphorylated $\mathrm{ABCA} 1{ }^{\mathrm{Ser} 2054}$. The EGFR selective inhibitor PD168393 blocked the EGFRABCA1 interaction and abolished ABCA1 ${ }^{\text {Ser2054 }}$ phosphorylation (Figure 6f). Thus, active EGFR interacts with ABCA1 and phosphorylated $A B C A 1^{\text {Ser2054 }}$. We asked whether the ABCA1 phosphorylation by EGFR contributes to the ubiquitination-mediated ABCA1 degradation. HeLa cells were transfected either with WT EGFR or with constitutively active EGFR mutant, along with exogenous ubiquitin (Ub; Supplementary Figure 4) and ABCA1. Both liganddependent stimulation of WT EGFR and activating EGFR 
mutant could enhance the formation of Ub-ABCA1 complex, with more dramatic effect being observed in the latter. In contrast, inhibition of EGFR activation by PD168393 abolished the interaction between $\mathrm{Ub}$ and $\mathrm{ABCA} 1$

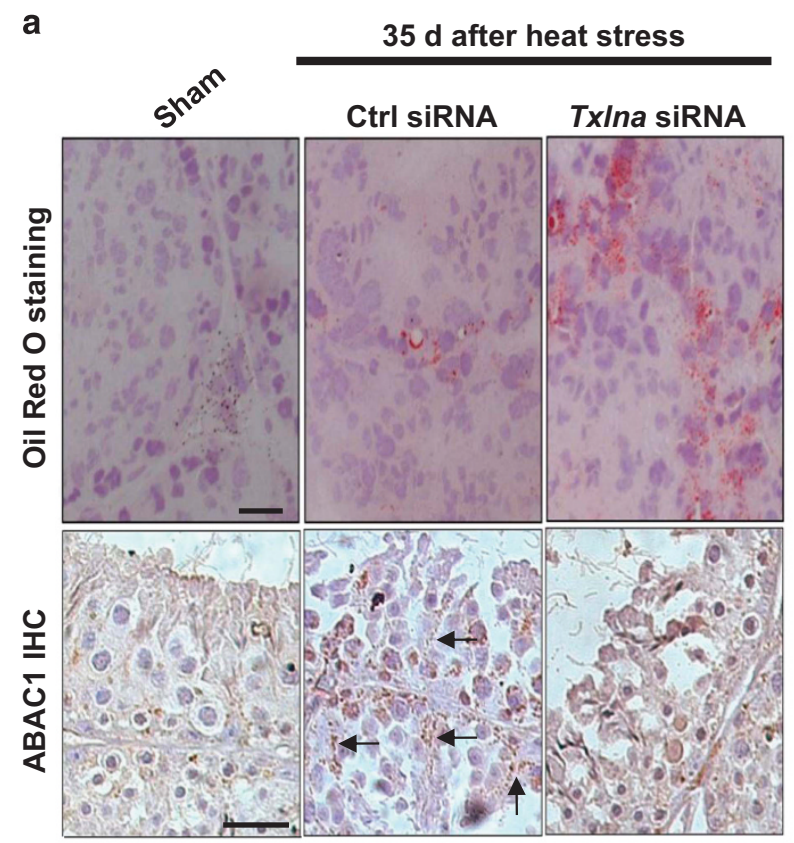

e

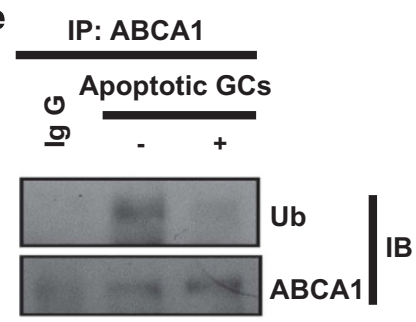

$\mathbf{h}$

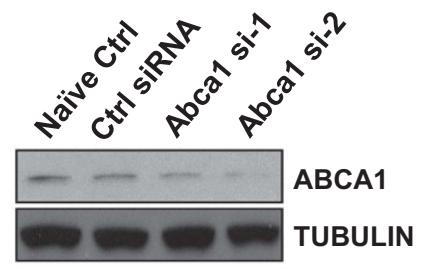

i

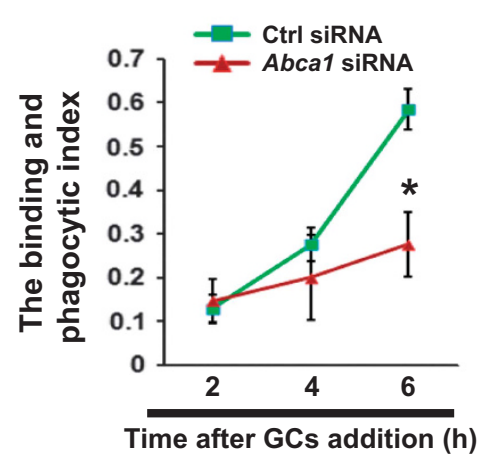

(Figure 6g). At last, treatment with PYR-41, an ubiquitin E1 inhibitor, ${ }^{30}$ or with PD168393, both markedly restored the binding and phagocytic activity in TXLNA-deficient SCs, at the end of 6-h incubation of apoptotic GCs (Figures 6h and i).
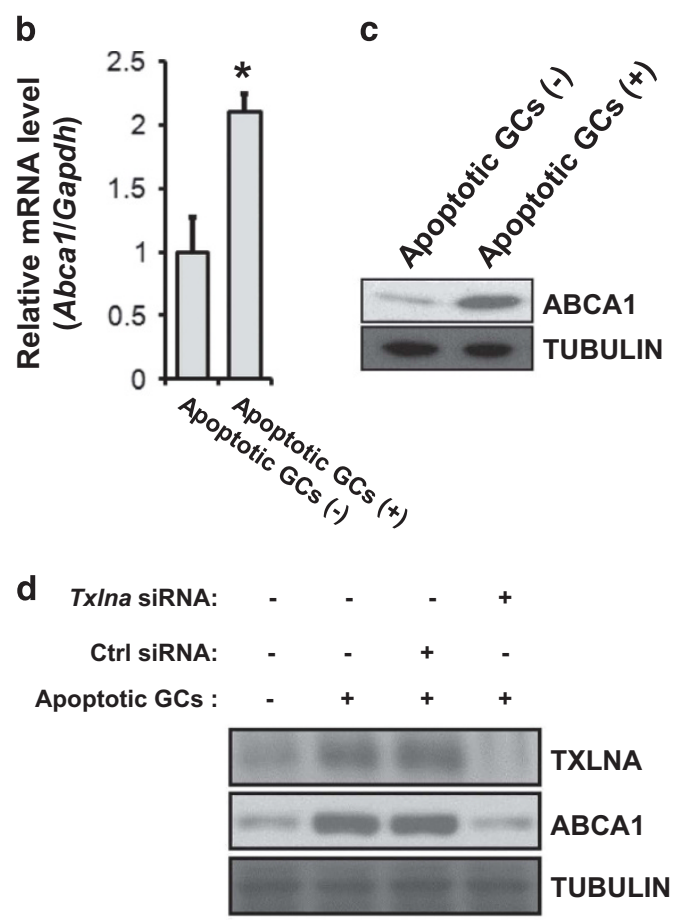

g

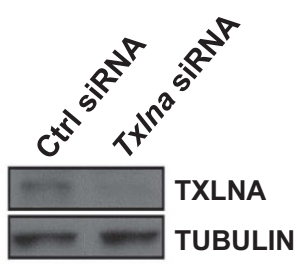

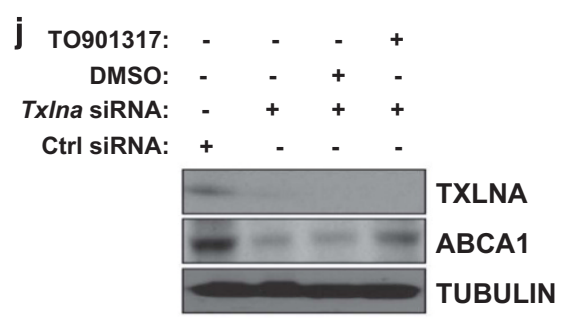

k

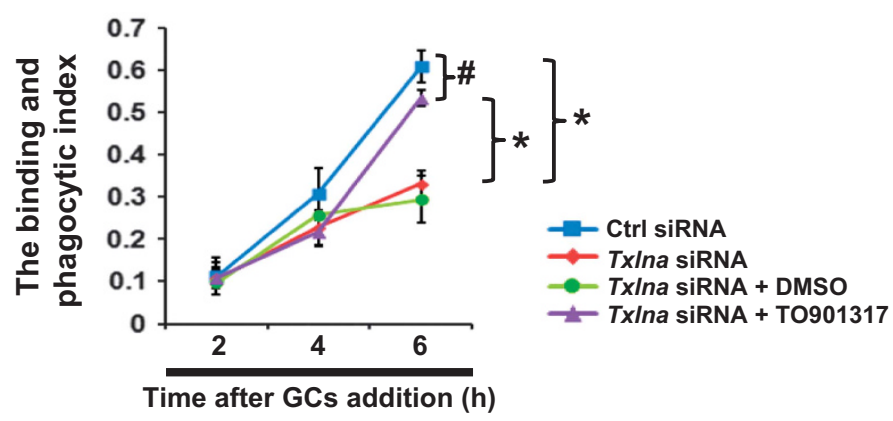




\section{Discussion}

Paracrine signaling between GCs and SCs regulates the homeostasis between these intimately associated cells. ${ }^{31}$ Intriguingly, upregulation of GC apoptosis failed to abolish TXLNA expression but resulted in a dramatic increase in TXLNA expression (Figures $2 e$ and $f$ ). Progression of $\mathrm{GCs}$ through the spermatogenic stages positively modulates expression of specific genes in SCs, and loss of distinct GC populations usually results in significant reduction of the expression levels in the latter. ${ }^{20}$ Our results suggest that TXLNA may not directly function in the Sertoli-GC adhesion junction. Instead, it may be associated with testicular phagocytosis because the latter is necessary for efficient clearance of apoptotic GCs. In addition, the most effective stimuli were apoptotic pachytene spermatocytes and haploid spermatids (Figure 2e). These data were in favor of the previous report that SC functions are crucially regulated by meiotic spermatocytes and postmeiotic spermatids. ${ }^{32}$

Validation of the functional importance of TXLNA expression in phagocytic activity was carried out using a transient mild testicular hyperthermia model. In control mice, a 20-min $\mathrm{HS}$ at $43^{\circ} \mathrm{C}$ resulted in a transient increase of meiotic apoptosis by $24 \mathrm{~h}$ after treatment, which returned to the normal level $14 \mathrm{~d}$ following heat exposure. Contrarily, TXLNA depletion using siRNA could partially restore the apoptotic wave during the recovery (Figures $3 e$ and f), indicative of a defect in SC phagocytosis caused by TXLNA deficiency. Consistently in the in vitro analyses, the phagocytic activity of SCs was substantially compromised when endogenous TXLNA expression was inhibited (Figures $3 \mathrm{~h}-\mathrm{j}$ ). Together, our data suggest that normal occurrence of SC phagocytosis requires normal level of TXLNA.

Another distinguishing feature is that at $70 \mathrm{~d}$ after $\mathrm{HS}$, when spermatogenesis is supposed to be mostly reconstituted, TXLNA deficiency still caused a significant decrease in the progressive motility of mature sperm and in the impregnation rate (Figure 4b). Thus, SC-expressing TXLNA may have a profound influence on the post-injury recovery of male fertility. Previously, blockage of SC phagocytosis by annexin $\mathrm{V}$ delays spermatogenic recovery in drug-treated mice and leads to the number of epididymal sperm to decrease. ${ }^{33}$ In our study, however, asthenozoospermia, not oligozoospermia, appeared to be responsible for the fertility impairment following HS (Figure 4b). Two reasons may help to explain this discrepancy. (i) SC phagocytosis may play different roles in response to various stimuli (e.g., drug stimulation versus HS). (ii) Our siRNA treatment failed to completely abolish TXLNA expression in SCs, so the remaining TXLNA may still be functional in phagocytic activity. An interesting study describes that teratospermic cats have a higher sperm output achieved by more GCs per SC, and reduced GC loss during spermatogenesis. $^{34}$ In this regard, stabilization of sperm quantity in TxIna siRNA-treated testis may be produced at the expense of sperm quality, such as motility and morphology. Although apoptosis usually serves to remove unwanted or potentially dangerous cells, there are some examples where apoptosis-like events do not lead to death but rather the unique differentiation of certain cell types. ${ }^{35,36}$ Therefore, once the disturbed GC apoptosis arises out of compromised phagocytosis in TxIna siRNA-treated testis, a morphologically abnormal terminal differentiation of sperm is very likely to occur.

Genes involved in appropriate regulation of lipid metabolism is critical for male fertility. ${ }^{37} \mathrm{ABCA} 1$ is such a striking example. ${ }^{9}$ However, the transcriptional or post-translational mechanisms responsible for controlling ABCA1 expression are poorly understood. Our findings extend these understanding by identifying ABCA1 as a downstream effector of TXLNA pathway. Stabilization of $A B C A 1$ protein level via repressing its ubiquitination by TXLNA may represent a novel mechanism contributing to the maintenance of SC phagocytosis. Several lines of evidence may support this assumption: (i) ABCA1 expression is abundant in SCs, whereas GCs express little ABCA1. More importantly, Sertoli TM4 cells can not efflux cholesterol to apoA1 due to the absence of $\mathrm{ABCA} 1{ }^{9}$ These results are highly consistent with our data. (ii) ABCA1 is essentially involved in phagocytosis. ${ }^{38,39}$ (iii) Ubiquitination has been associated with lysosomal degradation of cell surface-resident ABCA1 in $\mathrm{HuH}-7$ and THP-1 macrophages. $^{21}$ (iv) Accumulated data evidence a frequent participation of ubiquitination in the metabolism of syntaxin. ${ }^{40}$ By using an antibody-based ubiquitome analysis, $\mathrm{Na}$ et al. ${ }^{41}$ have demonstrated that a large number of synaptic proteins are modified by ubiquitination. In this context, TXLNA may regulate the ubiquitination of $A B C A 1$ via its interaction with distinct syntaxin during phagocytosis.

It has been reported that autophosphorylation of EGFR by ligand binding promotes its recognition by the ring-type E3, casitas B-lineage lymphoma $(\mathrm{Cbl}){ }^{42}$ To this end, it is attractively hypothesized that phosphorylation may serve as an initial key event in ubiquitination of $A B C A 1$ since the latter

Figure 5 Repression of $A B C A 1$ ubiquitination by TXLNA is required for the maintenance of ABCA1 stability during testicular phagocytosis. (a) Upper panels: Oil Red 0 staining of sham control, Ctrl siRNA or TxIna siRNA-treated testes at $35 \mathrm{~d}$ after heat treatment revealed lipid droplet accumulation in the last groups, with the much higher level being observed in the TxIna siRNA-treated testes. Lower panels: immunohistochemical analysis in the above-mentioned testes revealed a significant increase of ABCA1 expression in Ctrl siRNA-treated testes following heat stress, which was substantially abolished in TxIna siRNA-treated testes. Positive ABCA1 signals were indicated by black arrows. Scale bar, $25 \mu \mathrm{m}$. Effects of addition of apoptotic GCs on ABCA1 in cultured SCs were illustrated using qRT-PCR at transcriptional level (b) and western blotting at translational level (c); Gapdh and tubulin were served as internal controls. Data are presented as mean \pm S.E.M. of $\geq 3$ independent determinations. ${ }^{*} P<0.05$. (d) Effect of TXLNA deficiency on apoptotic GC-induced ABCA1 level in cultured SCs was evaluated using western blotting. (e) After incubation with apoptotic GCs for $6 \mathrm{~h}$, SCs were harvested, and lysates were subjected to a Co-IP assay followed by immunoblotting analysis to demonstrate the stimulatory effects of apoptotic GCs on ABCA1 expression. (f) Effects of TxIna knockdown in SCs by in vitro siRNA treatment were confirmed by western blotting. (g) TXLNA-deficient SCs were incubated with apoptotic GCs for $6 \mathrm{~h}$, followed by a Co-IP assay as described above. (h) Verification of Abca1 knockdown effect by siRNA treatment was performed using western blot analyses. (i) Effect of Abca1 knockdown on the binding and phagocytosis index. ${ }^{*} P<0.05$ when compared between Ctrl siRNA or TxIna siRNA-treated groups at the same time point. (j) Ctrl siRNA or TxIna siRNA-treated SCs were treated with T0901317 $(10 \mu \mathrm{M})$ for $24 \mathrm{~h}$, followed by immunoblotting analysis of TXLNA and ABCA1 levels. (k) Effect of ABCA1 rescue by TO901317 on the binding and phagocytosis index in TXLNA-deficient SCs. ${ }^{\#} P>0.05$ or ${ }^{*} P<0.05$ when compared between different groups at the end of $6 \mathrm{~h}$ 
a

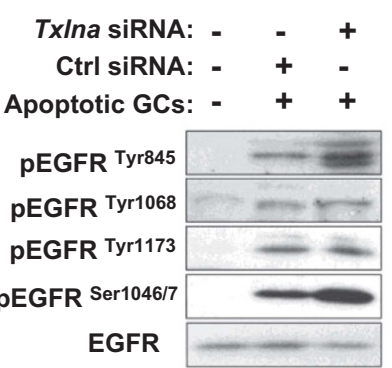

C PD 168393: - $\quad$ - $\quad$ - +

TxIna siRNA: - -++

Ctrl siRNA: - + - -

Apoptotic GCs: : - + + +

IP: ABCA1

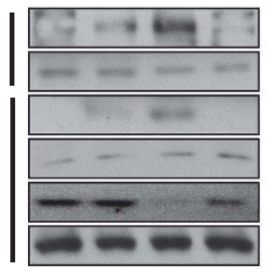

EGFR

ABCA1

pEGFR

EGFR

ABCA1

TUBULIN

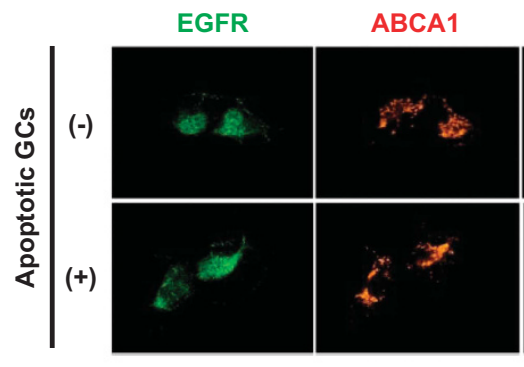

d

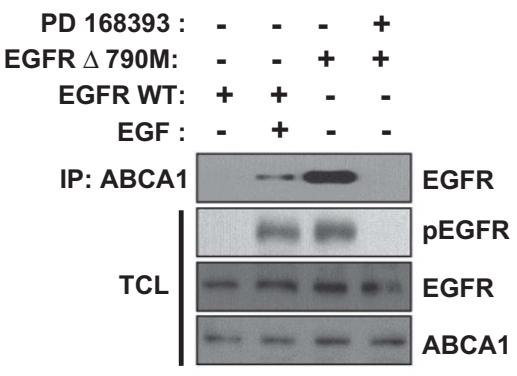

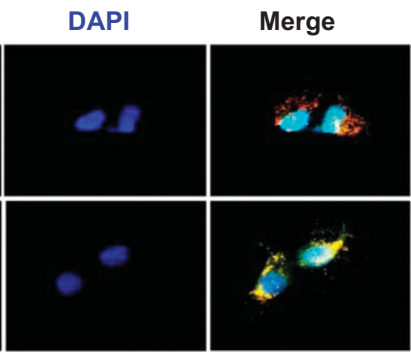

e

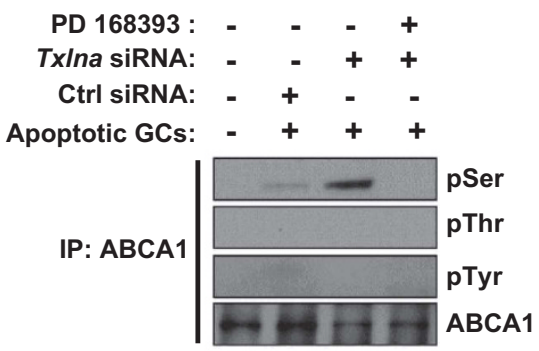

f PD 168393: : $\quad-\quad-\quad+$

EGFR $\triangle 790 \mathrm{M}: \quad-\quad-\quad+$

EGFR WT: + + - -

EGF : - + - -

IP: ABCA1

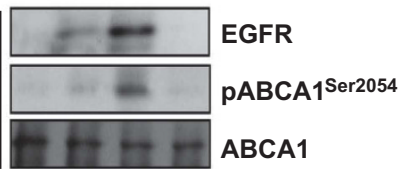

$\begin{array}{rllll}9 \\ \text { PD 168393 : } & - & - & - & + \\ \text { EGFR } \triangle 790 M: & - & - & + & + \\ \text { EGFR WT: } & + & + & - & - \\ \text { EGF : } & - & + & - & -\end{array}$

IP: ABCA1 $\begin{aligned} & \text { Ub } \\ & \text { ABCA1 }\end{aligned}$

h

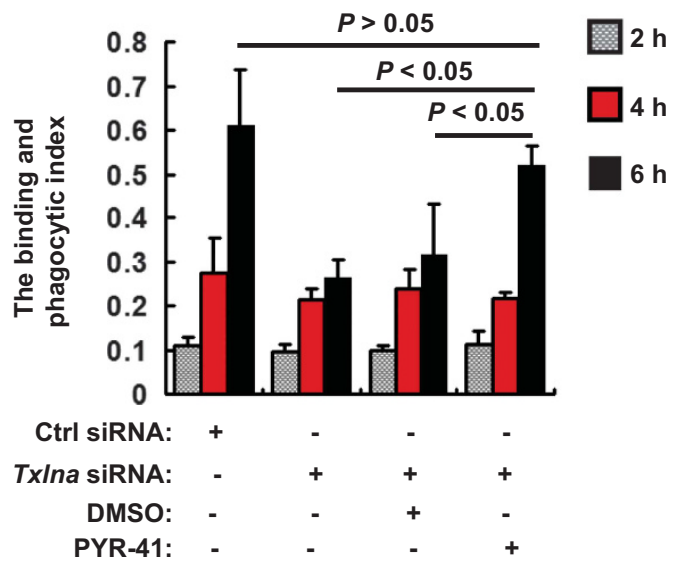

i

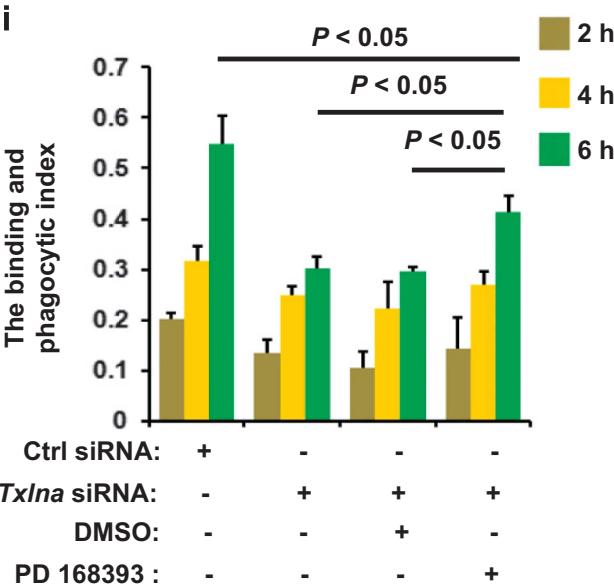

Figure 6 Epidermal growth factor receptor (EGFR)-mediated phosphorylation regulates ABCA1 ubiquitination and is enhanced by TXLNA deficiency during testicular phagocytosis. (a) Primary cultured SCs were incubated with apoptotic GCs for $45 \mathrm{~min}$. Subsequently, cells were harvested and whole-cell lysates were immunoblotted with phospho-EGFR (Tyr845, Tyr1068, Tyr1173 and Ser1046/7) and EGFR. (b) SCs were incubated with apoptotic GCs for 45 min, followed by immunofluorescence analysis of colocalization of EGFR and ABCA1. Nuclear are demonstrated using DAPI staining. (c) Ctrl siRNA or Txlna siRNA-transfected SCs were incubated with apoptotic GCs, in the presence or absence of $10 \mu \mathrm{M}$ EGFR inhibitor (PD168393), for $6 \mathrm{~h}$. Cells were then harvested and subjected to immunoprecipitation of EGFR with ABCA1. Immunoblot analyses of expression levels of ABCA1, pEGFR, EGFR and tubulin were also performed in the total-cell lysates (TCL). (d) Immunoprecipitation of EGFR with anti-ABCA1 in HeLa cells cotransfected with His-ABCA1 and indicated EGFR plasmid. After O/N serum starvation, cells were treated \pm EGF ( $50 \mathrm{ng} / \mathrm{ml}, 30 \mathrm{~min})$. Cells transfected with EGFR $\Delta 790 \mathrm{M}$ were either treated with DMSO (PD168393 '-') or (10 $\mu$ M, 6 h; PD168393 ' + '). (e) Immunoprecipitation of ABCA1 with different phospho-specific antibodies in SCs in conditions shown in (c). (f) Immunoprecipitation of ABCA1 with PABCA1 ${ }^{\text {Ser2054 }}$ in SCs in conditions shown in (d). (g) Immunoprecipitation of ABCA1 with Ub in SCs transfected with His-ABCA1, HA-Ub as well as indicated EGFR plasmid in conditions shown in (d). (h) SCs transfected with Ctrl siRNA or Tx/na siRNA were pretreated with an Ub E1 inhibitor (PYR-41, $50 \mu$ M) for $2 \mathrm{~h}$, followed by analysis of the binding and phagocytic index as described in Materials and Methods. Values represent the mean \pm S.E.M. of three independent experiments. (i) SCs transfected with Ctrl siRNA or TxIna siRNA were pretreated with PD168393 inhibitor $(10 \mu \mathrm{M})$ for $6 \mathrm{~h}$, followed by the binding and phagocytic analysis as described in (h) 
has serine phosphorylation sites that negatively regulate ABCA1 expression. ${ }^{43}$ Here, we show that upon activation, EGFR interacts with ABCA1, promoting its serine phosphorylation and ubiquitination (Figures $6 c$ and $e-g$ ). This effect occurred in cells expressing WT EGFR upon EGF binding as well as in cells with activating mutant EGFR (Figures $6 \mathrm{~d}$ and $\mathrm{g}$ ). Therefore, EGFR signaling may regulate phagocytosis via its interaction with $A B C A 1$ during mitogenic signaling. The mechanism by which EGFR promotes the ubiquitinationmediated ABCA1 degradation involves EGFR interaction with Ser-2054 of ABCA1 (Figure 6f). In favor of this, it has been shown that Ser-2054 is the main phosphorylation site for protein kinase A and a single mutation in Ser-2054 could significantly attenuate ApoA-I-dependent phospholipid efflux. ${ }^{29}$ Therefore, phosphorylation of this site is crucial for the regulation of $A B C A 1$ transporter activity. In addition, our results have direct implications for the regulation of EGFR activity by TXLNA during testicular phagocytosis. Further studies to explore in detail the interactions among TXLNA/ syntaxin cascade, EGFR signaling and the E3, which enables it to ubiquitinate $A B C A 1$, will expand the understanding of the molecular mechanism of ubiquitination-mediated ABCA1 degradation in the phagosome.

In summary, we propose a novel role of SC-expressing TXLNA (Figure 7). The TXLNA/ABCA1 cascade may serve as an important feedback mechanism to modulate the magnitude of subsequent phagocytic process of SCs in response to testicular injury.

\section{Materials and Methods}

Animal treatment. All animal work was approved by the Animal Care and Use Committee of the Fourth Military Medical University and the protocols were strictly conformed to the Guide for the Care and Use of Laboratory Animals published by the National Institutes of Health (NIH publication No. 85-23, revised 1996). All surgeries were performed under sodium pentobarbital anesthesia $(0.04-0.05 \mathrm{mg} / \mathrm{g}$ body weight, i.p.), and all efforts were made to minimize suffering. Pregnant C57BL/ 6 mice at $14 \mathrm{~d}$ of gestation and sexually mature C57/BL6 male mice (10 weeks of age) were obtained from the Animal Research Center of our university. They were housed in plastic boxes individually and provided standard mouse food pellets and water ad libitum throughout the study. At postnatal d 5, 10, 23 and 35, mice were killed under diethyl ether anesthesia, followed by cervical dislocation. Testicular heat stress model was induced according to our previous report. ${ }^{44}$ Briefly, after anesthetization, the lower third of the body (hind legs, tail and scrotum) was submerged in a water bath of $43^{\circ} \mathrm{C}$ for $20 \mathrm{~min}$. Animals were then dried and returned to their cages. Control animals were anesthetized and left at room temperature. Mice were killed at $24 \mathrm{~h}$ or $14 \mathrm{~d}$ after hyperthermal exposure. For histological studies, some testes were fixed in Bouin's solution for $24 \mathrm{~h}$, embedded in paraffin and processed into $5-\mu \mathrm{m}$-thick sections. For biochemical analysis, tissues were stored at $-80^{\circ} \mathrm{C}$ until use.

Cell treatment. 3T3, TM3, TM4 and HeLa cell lines were obtained from the American Type Culture Collection (Manassas, VA, USA) and maintained in Dulbecco's modified Eagle's medium (DMEM; Invitrogen, Shanghai, China) supplemented with $10 \%$ fetal calf serum (FCS; Invitrogen). Primary SCs were prepared as described previously. ${ }^{44}$ Briefly, testes were decapsulated and seminiferous tubules were dispersed in $0.1 \%$ collagenase (type IV) and $0.04 \%$ DNase I (all from Sigma-Aldrich, Beijing, China) in $1 \times$ Hanks fluid (pH 7.4) at $34^{\circ} \mathrm{C}$ for 10-15 min with constant shaking (100 oscillations per minute). The seminiferous tubules were incubated in $1 \times$ Hanks fluid $(\mathrm{pH} 7.4)$ containing $0.04 \%$ DNase I, $0.05 \%$ hyaluronidase, and $0.5 \%$ trypsin for at least $10 \mathrm{~min}$ at $34^{\circ} \mathrm{C}$ with agitation. The fragmented tubules were allowed to settle and cells were subsequently centrifuged at $900 \times g$ and at $700 \times g$ (each for $3 \mathrm{~min}$ ). Cells in the supernatant were collected and cultured (in DMEM/F-12 medium containing 5\% FCS) overnight. SCs attached to the bottom and acquired an irregular shape, whereas the GCs did not attach and could easily be removed by repeated washing. Cells were plated on 12well dishes coated with Matrigel (Collaborative Biochemical Products, Bedford, MA, USA) in $1: 1(\mathrm{v} / \mathrm{v})$ nutrient mixture F-12/DMEM and cultured for $48 \mathrm{~h}$ before being subjected to the hypotonic treatment with $20 \mathrm{mM}$ Tris ( $\mathrm{pH} 7.4$ ) for $2.5 \mathrm{~min}$ to further

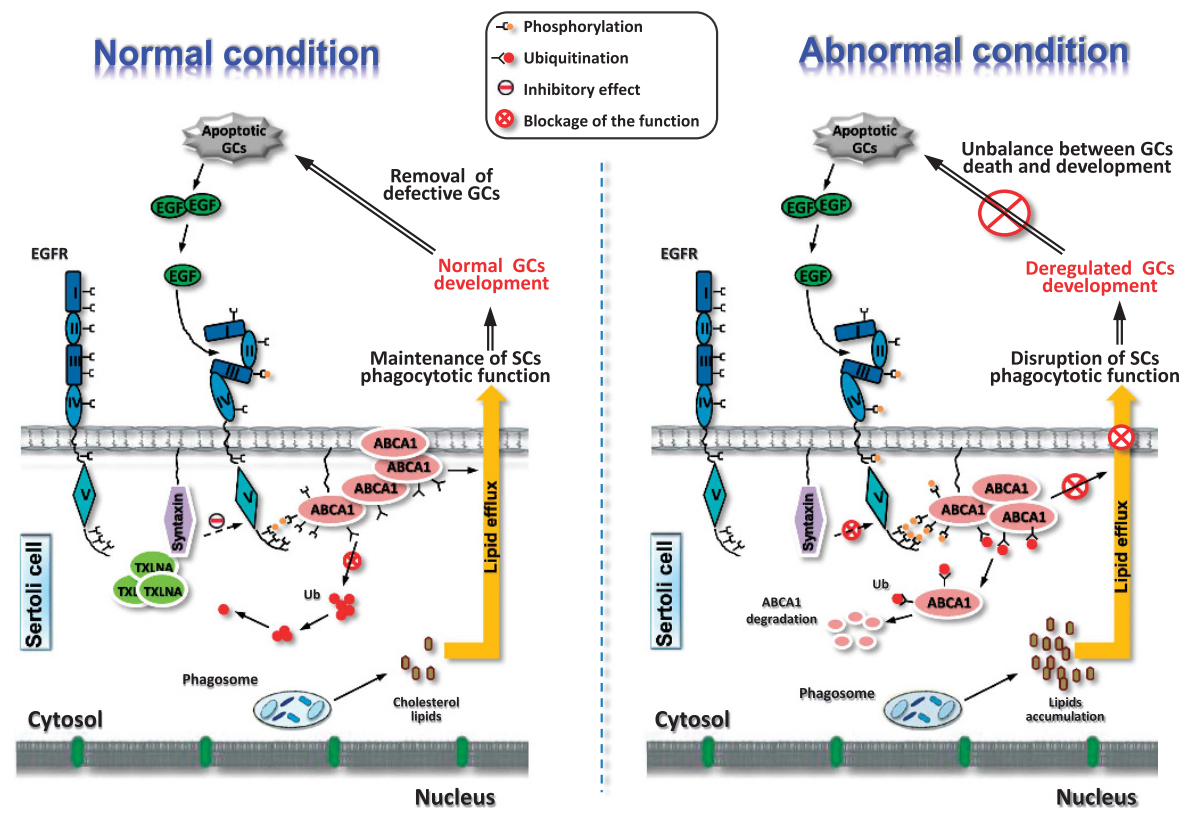

Figure 7 Summary diagram of the possible mechanisms related to TXLNA function contributing to maintenance of the apoptotic balance during testicular phagocytosis. GC apoptosis induces a significant increase in TXLNA expression, which inhibits ubiquitination and degradation of ABCA1 via suppression of EGFR phosphorylation, and then facilitates phagocytic activity of SCs. Removal of defective GCs via SC phagocytosis is crucial for homeostasis maintenance during normal spermatogenesis. Conversely, ablation of TXLNA, which causes EGFR hyperphosphorylated during phagocytosis, may result in the disruption of the ubiquitination of ABCA1 protein and the inevitable ABCA1 instability, followed by an unusual inhibition of the SC phagocytosis. Disruption of SC phagocytotic function causes imbalance between GC death and development, and finally leads to dyszoospermia 
lyse residual GCs, followed by two successive washes with F-12/DMEM to remove cell debris. The purity of these SC cultures was routinely analyzed by qRT-PCR according to our previous report. ${ }^{12}$ GCs were prepared according to our previous report. ${ }^{4}$ In brief, testes were decapsulated and digested for $15 \mathrm{~min}$ in $0.25 \%(\mathrm{w} / \mathrm{v})$ collagenase (type IX, Sigma-Aldrich) at room temperature with constant shaking. Seminiferous tubules were then cut in pieces using a sterile blade and further digested in minimum essential medium containing $1 \mathrm{mg} / \mathrm{ml}$ trypsin for $30 \mathrm{~min}$ at $30^{\circ}$ C. Digestion was stopped by adding $10 \% \mathrm{FCS}$ and the released GCs were collected after sedimentation (10 min at room temperature) of tissue debris. GCs were centrifuged for $10 \mathrm{~min}$ at $1,500 \times \mathrm{g}$ at $4^{\circ} \mathrm{C}$ and the pellet was resuspended in $20 \mathrm{ml}$ of elutriation medium $\left(120.1 \mathrm{mM} \mathrm{NaCl}, 4.8 \mathrm{mM} \mathrm{KCl}, 25.2 \mathrm{mM} \mathrm{NaHCO}_{3}, 1.2 \mathrm{mM}\right.$ $\mathrm{KH}_{2} \mathrm{PO}_{4}, 1.2 \mathrm{mM} \mathrm{MgSO}_{4}\left(7 \mathrm{H}_{2} \mathrm{O}\right), 1.3 \mathrm{mM} \mathrm{CaCl}, 11 \mathrm{mM}$ glucose, $1 \times$ essential amino acid (Life Technologies, Inc., Beijing, China), penicillin, streptomycin and $0.5 \% \mathrm{BSA}$ ). GCs were then cultured in minimum essential medium (Gibco, Beijing, China) and supplemented with $0.5 \%$ BSA (Sigma-Aldrich), $1 \mathrm{mM}$ sodium pyruvate and $2 \mathrm{mM}$ lactate at $32{ }^{\circ} \mathrm{C}$ in a humidified atmosphere containing $95 \%$ air and $5 \%$ $\mathrm{CO}_{2}$. Subsequently, GCs were cultured alone for another $2 \mathrm{~d}$ to induce spontaneous apoptosis. ${ }^{45}$ To determine the effect of EGFR and Ub on phagocytosis, cells were treated with $10 \mu \mathrm{M}$ EGFR inhibitor (PD168393, EMD Biosciences, San Diego, CA, USA) and $50 \mu \mathrm{M}$ Ub inhibitor (PYR-41, Sigma-Aldrich), respectively, for different durations as indicated in figure legends. To rescue ABCA1 level, cells were treated with $10 \mu \mathrm{M}$ T0901317 (Cayman Chemical, Ann Arbor, MI, USA) for $24 \mathrm{~h}$ before further analysis.

Cell transfection. EGFR WT-GFP was a gift from Alexander Sorkin (Addgene plasmid \# 32751; Cambridge, MA, USA). ${ }^{46}$ pBabe EGFR $(\Delta T 790 M)$ was a gift from Matthew Meyerson (Addgene plasmid \# 32070). ${ }^{47}$ pRK5-HA-Ubiquitin-WT was a gift from Ted Dawson (Addgene plasmid \# 17608). ${ }^{48}$ pPM-C-His-ABCA1 was purchased from Applied Biological Materials Inc. (Richmond, BC, Canada). HeLa/ GFP-EGFR or EGFR $\triangle 790 \mathrm{M} / \mathrm{His}-\mathrm{ABCA} 1$ cell lines were generated by sequential transfection of EGFR WT-GFP/pBabe EGFR $(\triangle T 790 \mathrm{M})$ and pPM-C-His-ABCA1 followed by sequential selection with $50 \mu \mathrm{g} / \mathrm{ml}$ kanamycin $/ 50 \mathrm{ng} / \mathrm{ml}$ puromycin and $0.5 \mu \mathrm{g} / \mathrm{ml} \mathrm{G} 418$ (Invitrogen). The positive clones were collected as a pool for subsequent transfection with pRK5-HA-Ubiquitin. Plasmid transfection was performed using Lipofectamine 2000 (Invitrogen) according to the manufacturer's instructions.

Western blotting. Western blotting was carried out as described in our previous work. ${ }^{49}$ Protein samples were prepared in ice-cold RIPA buffer (Tris- $\mathrm{HCl}$ $50 \mathrm{mM}, \mathrm{NaCl} 150 \mathrm{mM}$, Triton X-100 1\% (vol/vol), sodium deoxycholate 1\% (wt/vol) and SDS $0.1 \%$ (wt/vol), pH 7.5) supplemented with complete proteinase-inhibitor cocktail tablets (Roche Diagnostic, Shanghai, China). Approximately, $20 \mu \mathrm{g}$ of total protein was separated on SDS-PAGE and transferred to nitrocellulose membrane (Millipore, Bedford, MA, USA). Membranes were then incubated with different primary antibodies, as indicated in Supplementary Table 1, in blocking solution overnight at $4^{\circ} \mathrm{C}$. Final signals were detected using an ECL kit (Amersham Biosciences, Shanghai, China).

In vitro small interfering RNA (siRNA) treatment. Specific knockdown of endogenous $\alpha$-taxilin was achieved by transfecting 3T3 or SCs with corresponding siRNA against TxIna (sc-44830) or with a control siRNA (sc-37007; Santa Cruz Biotechnology, Paso Robles, CA, USA). Briefly, $2 \times 10^{5}$ cells were cultured in six-well culture plates and transfected with siRNA against TxIna (which consist of pools of three to five target-specific 19-25 nt siRNAs) or the same amount of non-target control siRNA following the manufacturer's protocol. Forty-eight hours after transfection, cells were collected and subjected to other experiments.

We designed and synthesized chemically two siRNA sequences targeting ABCA1 (GenBank accession number: NM_000313.3; Ruibo Co., Shanghai, China). The oligo sequences used were as follows: si-1 (sense: $5^{\prime}$-gaaccucacuuucagaagaUU-3'; antisense: $3^{\prime}$-UUcuuggagugaaagucuucu- $5^{\prime}$ ); si-2 (sense: $5^{\prime}$-guggccuggccucuauuu aUU-3'; antisense: $3^{\prime}-$ UUcaccggaccggagauaaau- $5^{\prime}$ ). ABCA1-siRNAs or a nonsilencing scrambled control siRNA (Altogen Biosystems, Las Vegas, NY, USA) were transfected into SCs using Lipofectamine 2000 (Invitrogen). Forty-eight hours after transfection, cells were collected and subjected to other experiments.

Immunofluorescence and immunohistochemistry. Immunōuorescence analysis was carried out as described elsewhere. ${ }^{50}$ Cells were fixed with $4 \%$ paraformaldehyde for $20 \mathrm{~min}$ followed by incubation with blocking solution
(10\% donkey serum, $0.5 \%$ BSA and $0.3 \%$ Triton $X-100$ in PBS). Cells were then treated with TXLNA antibody for overnight at $4{ }^{\circ} \mathrm{C}$. The immunoreactions were revealed by incubation of the cells with goat anti-rabbit FITC 488-conjugated IgG (Sigma-Aldrich) and DAPI (1: 5000, Sigma-Aldrich) for $10 \mathrm{~min}$. Staining was finally analyzed by microscopy using an inverted microscope (Axio Imager M1 microscope, Zeiss, Germany).

Streptavidin-biotin complex (SABC) immunohistochemical method was conducted as previously described. ${ }^{49}$ Briefly, after deparaffinization and rehydration, antigen retrieval was performed by incubating slides in $0.01 \%$ citrate acid in a preheated water bath $\left(95-100^{\circ} \mathrm{C}\right)$ for $30 \mathrm{~min}$ and then cooling to room temperature. Sections were then exposed to $0.3 \%$ hydrogen peroxide in methanol for $10 \mathrm{~min}$ to destroy endogenous peroxides activity, followed by incubation with primary antibodies at $4{ }^{\circ} \mathrm{C}$ overnight in a moist box. Biotinylated secondary antibodies were incubated on the sections for $1 \mathrm{~h}$ at room temperature and detected with streptavidin-peroxidase complex. Peroxidases were detected with $0.7 \mathrm{mg} / \mathrm{ml} 3,3^{\prime}$-diaminobenzidine tetrahydrochloride (Sigma-Aldrich, St. Louis, MO, USA) in $1.6 \mathrm{mg} / \mathrm{ml}$ urea hydrogen peroxide. Control slides were incubated with a nonimmune serum (Sino Biological Inc., Beijing, China) instead of primary antibody.

Measurement of apoptosis. TUNEL assay was done using in situ cell death detection kit (Roche Applied Science, Mannheim, Germany) as described previously. ${ }^{51}$ Slides were saturated with $50 \mu \mathrm{l}$ of an equilibration buffer (EB: $200 \mathrm{mM}$ K-cacodylate, $25 \mathrm{mM}$ Tris- $\mathrm{HCl}$ (pH 6.6), $0.2 \mathrm{mM} \mathrm{DTT}, 0.25 \mu \mathrm{g} / \mu \mathrm{l}$ BSA and $2.5 \mathrm{mM}$ $\mathrm{CoCl}_{2}$ ) under a plastic coverslip (Millipore, Beijing, China) to prevent evaporation for $10 \mathrm{~min}$, followed by the incubation with the TUNEL reaction mixture and $1 \mu \mathrm{l}$ of $25 \mathrm{U} / \mu$ l of terminal deoxynucleotidyl transferase. The TUNEL reaction mixture was evenly spread under a plastic coverslip, and slides were incubated at $37^{\circ} \mathrm{C}$ for $1 \mathrm{~h}$. The reaction was terminated by immersing the slides in $2 x$ sodium chloride and sodium citrate ( $2 \times$ SSC: $300 \mathrm{mM} \mathrm{NaCl}$ and $30 \mathrm{mM} \mathrm{Na}$-citrate, $\mathrm{pH} 7.4$ ) for $15 \mathrm{~min}$ at room temperature. Slides were finally mounted with $80 \%$ glycerol. Positive signals were visualized on an inverted microscope (Axio Imager M1 microscope). Apoptotic cells would exhibit a green nuclear stain under microscope and were quantitatively counted manually in a masked manner, as described previously. ${ }^{52}$ Results were presented as both TUNEL-positive cells per $10^{3}$ cells.

The double-labeling assay for detecting apoptotic cells and cyclin A1-positive cells was carried out as described elsewhere. ${ }^{13}$ Briefly, after slides had been stained with TUNEL kit as described above, slides were washed three times in PBS for $10 \mathrm{~min}$. In order to reduce non-specific background, the sections were blocked with $2 \%$ sheep and horse sera in PBS for $30 \mathrm{~min}$ at room temperature. The sections were then incubated with the blocking solution containing cyclin A1 antibody (1:200, Santa Cruz Biotechnology), at $4{ }^{\circ} \mathrm{C}$ overnight in a moist box. Slides were washed three times in PBS for 10 min prior to addition of rhodamine-labeled antibodies (Jackson ImmunoResearch Laboratories, West Grove, PA, USA). The sections were mounted in $80 \%$ glycerol and examined with an inverted microscope.

Quantitative RT-PCR. Total RNA was extracted from murine testes using RNeasy Mini kit (Qiagen Inc., Valencia, CA, USA) according to the manufacturer's instructions. Routine DNase (Applied Biosystems/Ambion, Austin, TX, USA) treatment ( $1 \mathrm{U}$ of DNase $1 / \mu \mathrm{g}$ of total RNA) was performed before reverse transcription (RT). First-strand cDNA was synthesized with SuperScript III (RNase $\mathrm{H}$-reverse transcriptase; Invitrogen) and PCR was set up according to Promega's reverse transcription system protocol. Primers used were: Txlna (GenBank: NM_001005506.3), forward 5'-GTGGCATTCGGGAGAAAG-3' and reverse 5'-AGA AATCCCCAAATCTGACG-3'; Abca1 (NM_013454.3), forward 5'-TTTGAAAAACCA GTTGGGAA-3' and reverse 5'-AAACACTGTCCTCCTTTTTC-3'. Other primers used were reported in our previous report. Amplification of Gapdh was served as the internal control. PCR products were then quantified by SYBR green intercalation using the MiniOpticon system (Bio-Rad Laboratories, Inc., Hercules, CA, USA). Gapdh was used to obtain the $\Delta \Delta \mathrm{Ct}$ values for the calculation of fold increases.

The binding and phagocytosis assay. RBs were isolated from testes of 70-d-old mice according to our previous work. ${ }^{14}$ RBs were then transferred into labeling buffer (10 mM Na borate (pH 8.8), $150 \mathrm{mM} \mathrm{NaCl})$, followed by incubation in biotin labeling solution $\left(50 \mu \mathrm{g} / \mathrm{ml}\right.$ in DMSO) at $20^{\circ} \mathrm{C}$ for $15 \mathrm{~min}$. The labeling was ended by adding $10 \mathrm{mM} \mathrm{NH}_{4} \mathrm{Cl}$. To measure RBs phagocytic activity, SCs seeded in eight-well Lab-Tek chambers (Sigma-Aldrich) were incubated with $1.2 \times 10^{7}$ biotinylated RBs for 2,4 or 6 at $34^{\circ} \mathrm{C}$ in a humidified atmosphere of $5 \% \mathrm{CO}_{2}$. Unbound RBs were washed away with DMEM, and cells were fixed for 5 min with $4 \%$ paraformaldehyde. Subsequently, RBs were labeled with avidin-FITC for $1 \mathrm{~h}$ at 
$25^{\circ} \mathrm{C}$. The positive green cells were observed using an inverted microscope, and the binding and phagocytic index was calculated as the ratio of positive green signals/cell number in each well. Of note, we could not discriminate plasma membrane-bound RBs from engulfed RBs, so the endpoint of this assay should be considered as a combination of both binding and phagocytosis.

SiRNA treatment of adult mice. In vivo siRNA for ablation of endogenous TxIna in testis was carried out according to the protocol established previously. ${ }^{15}$ Animals were injected i.p. with $100 \mu$ l solution of siRNA daily for $10 \mathrm{~d}$ in isotonic saline solution ( $3 \mu \mathrm{g}$ per mouse), followed by a 14-d break. This duration was chosen because the inhibitory effect of siRNA on endogenous TxIna maintained a relatively stable level of 2 weeks after administration (data not shown). Mice received four cycles of in vivo siRNA treatment as indicated in Figure 4a.

Evaluation of reproductive capacity and characterization of epididymal sperms after heat stress. Fertility tests were done at 35 or 70 $\mathrm{d}$ after heat stress, according to the method described previously. ${ }^{53}$ Males were individually housed with different wild females for $9 \mathrm{~d}$, and were then set up again with other females for an additional $9 \mathrm{~d}$. Females with the presence of copulation plugs were observed for pregnancy and litter size. The cauda region of the right epididymis was placed in $0.1 \mathrm{ml}$ of motile buffer $(120 \mathrm{mM} \mathrm{NaCl}, 5 \mathrm{mM} \mathrm{KCl}, 25 \mathrm{mM}$ $\mathrm{NaHCO}_{3}, 1.2 \mathrm{mM} \mathrm{KH}_{2} \mathrm{PO}_{4}, 1.2 \mathrm{mM} \mathrm{MgSO}_{4}$ and $1.3 \mathrm{mM} \mathrm{CaCl}_{2}$ ). Tissue was then gently minced using sterilized scissors and incubated it at $37^{\circ} \mathrm{C}$ for $5 \mathrm{~min}$ to allow sperm dispersal. The supernatant was obtained as a sperm suspension, and the motility of sperm in the suspension was visually monitored under phase-contrast images (Olympus, Queens, NY, USA). After 25-fold dilution, the number of sperm in the $0.1-\mu$ l suspension was counted by using cell counter plates (Invitrogen, Beijing, China) under the microscope. Sperm morphology was assessed in concert with trypan blue stain as described elsewhere. ${ }^{54}$

Oil Red O (ORO) staining. The lipid droplets inside seminiferous tubules were visualized by ORO staining. ${ }^{4}$ Testes were harvested at $35 \mathrm{~d}$ after heat stress and frozen sections of 8- $\mu \mathrm{m}$ thickness were sliced with a microtome (Leica, Wetzlar, Germany). After 40-min fixation with 10\% formalin, sections were stained with ORO solution (Sigma-Aldrich, ORO-saturated solution in isopropanol: water, 3:2) for $15 \mathrm{~min}$. The background staining was removed by rinsing the slides with $70 \%$ alcohol. The lipid droplets were finally analyzed under a microscope (Axio Imager M1 microscope).

Co-immunoprecipitation (Co-IP). Cells were collected at the end of $6 \mathrm{~h}$ after addition of apoptotic GCs. Lysates were obtained by lysing cells in IP lysis buffer (10 mM Tris, $0.15 \mathrm{M} \mathrm{NaCl}, 1 \%$ Nonidet P-40 (Sigma-Aldrich) and 10\% glycerol, $\mathrm{pH} 7.4$ at $22^{\circ} \mathrm{C}$ ) supplemented with protease and phosphatase inhibitor mixtures (Roche Diagnostic, Mannheim, Germany), sonicating and centrifuging at $15,000 \times \mathrm{g}$ for $20 \mathrm{~min}$ to obtain the clear supernatant. The lysates $(\sim 200 \mu \mathrm{g})$ were incubated with primary antibodies or control $\lg$ antibodies at $4^{\circ} \mathrm{C}$ overnight. On the following day, protein A-Sepharose (Pierce, Rockford, IL, USA) was added into lystates and the compound was incubated at $4{ }^{\circ} \mathrm{C}$ for another $2 \mathrm{~h}$. Immunocomplexes were finally eluted from the Sepharose beads (Rockland Immunochemicals Inc. Limerick, PA, USA) by boiling in Laemmli sample buffer (Sigma-Aldrich) and subjected to SDS-PAGE of immunoblotting analysis with anti$\mathrm{Ub}$ antibody as described above.

Statistical analysis. Results are presented as mean \pm S.E.M. from at least three independent experiments, and were analyzed for statistically significant differences using Student's $t$-test or analysis of variance (ANOVA). A P-value of $<0.05$ was considered statistically significant. Statistical analyses were performed by using SPSS 15.0 software (IBM, Somers, NY, USA).

\section{Conflict of Interest}

The authors declare no conflict of interest.

Acknowledgements. We are grateful to Ms. Hui Wang (Department of Foreign Language, Fourth Military Medical University, China) for her careful assistance during the preparation of the manuscript. This work was supported by the National Natural Science Foundation of China (NSFC): 31271248, 31440064, 81300956 and 81371446.
1. Xiong W, Chen Y, Wang $H$, Wu H, Lu Q, Han D. Gas6 and the Tyro 3 receptor tyrosine kinase subfamily regulate the phagocytic function of Sertoli cells. Reproduction 2008; 135 : 77-87.

2. Bailly A, Gartner A. Germ cell apoptosis and DNA damage responses. Adv Exp Med Biol 2013; 757: 249-276.

3. Shiratsuchi A, Kawasaki Y, Ikemoto M, Arai H, Nakanishi Y. Role of class B scavenger receptor type I in phagocytosis of apoptotic rat spermatogenic cells by Sertoli cells. J Biol Chem 1999; 274: 5901-5908.

4. Xiong $\mathrm{W}$, Wang $\mathrm{H}, \mathrm{Wu} \mathrm{H}, \mathrm{Chen} \mathrm{Y}$, Han D. Apoptotic spermatogenic cells can be energy sources for Sertoli cells. Reproduction 2009; 137: 469-479.

5. Horii Y, Sakane H, Nogami S, Ohtomo N, Tomiya T, Shirataki H. Expression of alpha-taxilin in the murine gastrointestinal tract: potential implication in cell proliferation. Histochem Cell Biol 2014; 141: 165-180.

6. Nogami S, Satoh S, Tanaka-Nakadate S, Yoshida K, Nakano M, Terano A et al. Identification and characterization of taxilin isoforms. Biochem Biophys Res Commun 2004; 319: 936-943.

7. Wang S, Smith JD. ABCA1 and nascent HDL biogenesis. Biofactors 2014; 40: 547-554.

8. Bared SM, Buechler C, Boettcher A, Dayoub R, Sigruener A, Grandl M et al. Association of ABCA1 with syntaxin 13 and flotillin-1 and enhanced phagocytosis in Tangier cells. Mol Biol Cell 2004; 15: 5399-5407.

9. Selva DM, Hirsch-Reinshagen V, Burgess B, Zhou S, Chan J, Mclsaac S et al. The ATPbinding cassette transporter 1 mediates lipid efflux from Sertoli cells and influences male fertility. J Lipid Res 2004; 45: 1040-1050.

10. Nakanishi Y, Shiratsuchi A. Phagocytic removal of apoptotic spermatogenic cells by Sertoli cells: mechanisms and consequences. Biol Pharm Bull 2004; 27: 13-16.

11. Sharpe RM, McKinnell C, Kivlin C, Fisher JS. Proliferation and functional maturation of Sertoli cells, and their relevance to disorders of testis function in adulthood. Reproduction 2003; 125: 769-784.

12. Sun H, Yang B, Zhu C, Liu R, Wang H, Li W. Presence of metastasis-associated protein 1 in Sertoli cells is required for proper contact between Sertoli cells and adjacent germ cells. Urology 2013; 81: 66-73.

13. Li W, Zeng Y, Zhao J, Zhu CJ, Hou WG, Zhang S. Upregulation and nuclear translocation of testicular ghrelin protects differentiating spermatogonia from ionizing radiation injury. Cell Death Dis 2014; 5: e1248.

14. Zhu CJ, Zhang S, Liang Y, Li W. Elicitation of metastasis associated protein 2 expression in the phagocytosis by murine testicular Sertoli cells. Biochem Biophys Res Commun 2014; 445: 667-672.

15. Gonzalez-Herrera IG, Prado-Lourenco L, Pileur F, Conte C, Morin A, Cabon F et al. Testosterone regulates FGF-2 expression during testis maturation by an IRES-dependent translational mechanism. FASEB J 2006; 20: 476-478.

16. Paul C, Murray AA, Spears N, Saunders PT. A single, mild, transient scrotal heat stress causes DNA damage, subfertility and impairs formation of blastocysts in mice. Reproduction 2008; 136: 73-84.

17. Paul C, Teng S, Saunders PT. A single, mild, transient scrotal heat stress causes hypoxia and oxidative stress in mouse testes, which induces germ cell death. Biol Reprod 2009; 80 913-919.

18. Yin $\mathrm{Y}$, Hawkins $\mathrm{KL}$, DeWolf WC, Morgentaler A. Heat stress causes testicular germ cell apoptosis in adult mice. J Androl 1997; 18: 159-165.

19. Zhu CC, Zhang H, Zhang JS, Li Z, Zhao J, Li W et al. Inhibition of ghrelin signaling improves the reproductive phenotype of male ob/ob mouse. Fertil Steril 2013; 99: 918-926.

20. Vernet N, Dennefeld C, Guillou F, Chambon P, Ghyselinck NB, Mark M. Prepubertal testis development relies on retinoic acid but not rexinoid receptors in Sertoli cells. EMBO J 2006; 25: $5816-5825$.

21. Hsieh V, Kim MJ, Gelissen IC, Brown AJ, Sandoval C, Hallab JC et al. Cellular cholesterol regulates ubiquitination and degradation of the cholesterol export proteins $A B C A 1$ and ABCG1. J Biol Chem 2014; 289: 7524-7536.

22. Di D, Wang Z, Liu Y, Luo G, Shi Y, Berggren-Soderlund $M$ et al. ABCA1 upregulating apolipoproein M expression mediates via the RXR/LXR pathway in HepG2 cells. Biochem Biophys Res Commun 2012; 421: 152-156.

23. Jutten B, Rouschop KM. EGFR signaling and autophagy dependence for growth, survival, and therapy resistance. Cell Cycle 2014; 13: 42-51.

24. Cadwell K, Philips JA. Autophagy meets phagocytosis. Immunity 2013; 39: 425-427.

25. Wei Y, Zou Z, Becker N, Anderson M, Sumpter R, Xiao G et al. EGFR-mediated Beclin 1 phosphorylation in autophagy suppression, tumor progression, and tumor chemoresistance. Cell 2013; 154: 1269-1284.

26. Remaley AT, Stonik JA, Demosky SJ, Neufeld EB, Bocharov AV, Vishnyakova TG et al. Apolipoprotein specificity for lipid efflux by the human ABCAl transporter. Biochem Biophys Res Commun 2001; 280: 818-823.

27. Hu YW, Ma X, Li XX, Liu XH, Xiao J, Mo ZC et al. Eicosapentaenoic acid reduces ABCA1 serine phosphorylation and impairs $A B C A 1$-dependent cholesterol efflux through cyclic AMP/protein kinase A signaling pathway in THP-1 macrophage-derived foam cells. Atherosclerosis 2009; 204: e35-e43.

28. Haidar B, Denis M, Krimbou L, Marcil M, Genest J Jr. cAMP induces ABCA1 phosphorylation activity and promotes cholesterol efflux from fibroblasts. J Lipid Res 2002; 43: 2087-2094.

29. See RH, Caday-Malcolm RA, Singaraja RR, Zhou S, Silverston A, Huber MT et al. Protein kinase A site-specific phosphorylation regulates ATP-binding cassette A1 (ABCA1)mediated phospholipid efflux. J Biol Chem 2002; 277: 41835-41842. 
30. Ungermannova D, Parker SJ, Nasveschuk CG, Chapnick DA, Phillips AJ, Kuchta RD et al. Identification and mechanistic studies of a novel ubiquitin E1 inhibitor. J Biomol Screen 2012; 17: $421-434$.

31. Boekelheide K, Fleming SL, Johnson KJ, Patel SR, Schoenfeld HA. Role of Sertoli cells in injury-associated testicular germ cell apoptosis. Proc Soc Exp Biol Med 2000; 225: 105-115.

32. Boujrad N, Hochereau-de Reviers MT, Carreau S. Evidence for germ cell control of Sertoli cell function in three models of germ cell depletion in adult rat. Biol Reprod 1995; 53: 1345-1352.

33. Maeda Y, Shiratsuchi A, Namiki M, Nakanishi Y. Inhibition of sperm production in mice by annexin $V$ microinjected into seminiferous tubules: possible etiology of phagocytic clearance of apoptotic spermatogenic cells and male infertility. Cell Death Differ 2002; 9: 742-749.

34. Neubauer K, Jewgenow K, Blottner S, Wildt DE, Pukazhenthi BS. Quantity rather than quality in teratospermic males: a histomorphometric and flow cytometric evaluation of spermatogenesis in the domestic cat (Felis catus). Biol Reprod 2004; 71: 1517-1524.

35. Fuchs $Y$, Steller H. Programmed cell death in animal development and disease. Cell 2011; 147: $742-758$

36. Said TM, Paasch U, Glander HJ, Agarwal A. Role of caspases in male infertility. Hum Reprod Update 2004; 10: 39-51.

37. Tvrda E, Knazicka Z, Bardos L, Massanyi P, Lukac N. Impact of oxidative stress on male fertility-a review. Acta Vet Hung 2011; 59: 465-484.

38. Hamon Y, Trompier D, Ma Z, Venegas V, Pophillat M, Mignotte V et al. Cooperation between engulfment receptors: the case of ABCA1 and MEGF10. PLoS One 2006; 1: e120.

39. Hamon $Y$, Broccardo $C$, Chambenoit $O$, Luciani MF, Toti F, Chaslin $S$ et al. ABC1 promotes engulfment of apoptotic cells and transbilayer redistribution of phosphatidylserine. Nat Cell Biol 2000; 2: 399-406.

40. Zhang L, Kang L, Bond W, Zhang N. Interaction between syntaxin 8 and HECTd3, a HECT domain ligase. Cell Mol Neurobiol 2009; 29: 115-121.

41. $\mathrm{Na} \mathrm{CH}$, Jones DR, Yang $\mathrm{Y}$, Wang $\mathrm{X}, \mathrm{Xu}$ Y, Peng J. Synaptic protein ubiquitination in rat brain revealed by antibody-based ubiquitome analysis. J Proteome Res 2012; 11: 4722-4732.

42. Levkowitz G, Waterman H, Ettenberg SA, Katz M, Tsygankov AY, Alroy I et al. Ubiquitin ligase activity and tyrosine phosphorylation underlie suppression of growth factor signaling by c-Cbl/Sli-1. Mol Cell 1999; 4: 1029-1040.

43. Mizuno T, Hayashi H, Naoi S, Sugiyama Y. Ubiquitination is associated with lysosomal degradation of cell surface-resident ATP-binding cassette transporter A1 (ABCA1) through the endosomal sorting complex required for transport (ESCRT) pathway. Hepatology 2011; 54: $631-643$

44. Li W, Wu ZQ, Zhao J, Guo SJ, Li Z, Feng X et al. Transient protection from heat-stress induced apoptotic stimulation by metastasis-associated protein 1 in pachytene spermatocytes. PLOS One 2011; 6: e26013.

45. Wang $\mathrm{H}$, Xiong W, Chen $\mathrm{Y}, \mathrm{Ma} \mathrm{Q}, \mathrm{Ma} J, \mathrm{Ge} Y$ et al. Evaluation on the phagocytosis of apoptotic spermatogenic cells by Sertoli cells in vitro through detecting lipid droplet formation by Oil Red O staining. Reproduction 2006; 132: 485-492.

46. Carter RE, Sorkin A. Endocytosis of functional epidermal growth factor receptor-green fluorescent protein chimera. J Biol Chem 1998; 273: 35000-35007.

47. Yuza Y, Glatt KA, Jiang J, Greulich H, Minami Y, Woo MS et al. Allele-dependent variation in the relative cellular potency of distinct EGFR inhibitors. Cancer Biol Ther 2007; 6: 661-667.

48. Lim KL, Chew KC, Tan JM, Wang C, Chung KK, Zhang Y et al. Parkin mediates nonclassical, proteasomal-independent ubiquitination of synphilin-1: implications for Lewy body formation. J Neurosci 2005; 25: 2002-2009.

49. Zhang S, Li W, Zhu C, Wang X, Li Z, Zhang J et al. Sertoli cell-specific expression of metastasis-associated protein 2 (MTA2) is required for transcriptional regulation of the follicle-stimulating hormone receptor (FSHR) gene during spermatogenesis. J Biol Chem 2012; 287: 40471-40483.

50. Mou L, Zhang Q, Wang Y, Sun L, Li C, Huang W et al. Identification of Ube2b as a novel target of androgen receptor in mouse sertoli cells. Biol Reprod 2013; 89: 32.

51. Chen S, Dong Y, Xu C, Jiang L, Chen Y, Jiang $C$ et al. Involvement of a chromatin modifier in response to mono-(2-ethylhexyl) phthalate (MEHP)-induced Sertoli cell injury: probably an indirect action via the regulation of NFkappaB/FasL circuitry. Biochem Biophys Res Commun 2013; 440: 749-755.

52. Jiang $X$, Bai $Y$, Zhang $Z$, Xin Y, Cai L. Protection by sulforaphane from type 1 diabetesinduced testicular apoptosis is associated with the up-regulation of Nrf2 expression and function. Toxicol Appl Pharmacol 2014; 279: 198-210.

53. Jiang M, Gao M, Wu C, He H, Guo X, Zhou Z et al. Lack of testicular seipin causes teratozoospermia syndrome in men. Proc Natl Acad Sci USA 2014; 111: 7054-7059.

54. Serafini R, Longobardi V, Spadetta M, Neri D, Ariota B, Gasparrini B et al. Trypan blue/ giemsa staining to assess sperm membrane integrity in salernitano stallions and its relationship to pregnancy rates. Reprod Domest Anim 2014; 49: 41-47.

\section{Supplementary Information accompanies this paper on Cell Death and Differentiation website (http://www.nature.com/cdd)}

